\title{
EL APORTE DEL TURISMO A LA ECONOMÍA COSTARRICENSE: MÁS DE UNA DÉCADA DESPUÉS
}

\author{
THE CONTRIBUTION OF TOURISM TO THE COSTA RICAN ECONOMY: OVER A \\ DECADE AFTER
}

\section{A CONTRIBUIÇÃO DO TURISMO PARA A ECONOMIA DA COSTA RICA: MAIS DE UMA DÉCADA DEPOIS}

\section{Shirley Benavides Vindas ${ }^{1}$}

\begin{abstract}
Resumen
En el año 2005, se publicó el último artículo relacionado con el aporte del turismo a la economía costarricense. Por ello y por la importancia de esta actividad para el país, se ha considerado su actualización y ampliación del análisis de los resultados generados, más de una década después de la primera publicación. Se trabajó con datos de fuentes oficiales, tanto nacionales como internacionales, que garanticen la confiablidad de la información generada, para el análisis en esos dos niveles. Se presenta un contexto internacional y el comportamiento de una serie de variables que posibilitan determinar el aporte a la economía costarricense. Las dos actividades que más aportan al turismo y a la economía en general son: los "productos característicos del turismo" y "servicios conexos del turismo". Estas son generadas, en su mayoría, por microempresas, con los riesgos que eso implica por ser las de más vulnerabilidad en el parque empresarial. El mayor productor y generador de valor es el relacionado con el "alojamiento" y, en segundo lugar, las "otras industrias conexas al turismo", las cuales posibilitan más y mejores encadenamientos productivos. Según el Banco Central de Costa Rica, el PIB turístico para el año 2016, último dato que se tiene, fue de 1554928 millones de colones [correspondientes a US\$ 2 712,6 millones], que representa un valor
\end{abstract}

Doi: https://doi.org/10.15359/eys.25-57.1

Recibido: 03-05-2019. Reenvíos: 07-05-2019, 15-10-2019, 17-09-2019, 17-10-2019, 13-11-2019. Aceptado: 17-102019. Publicado: 01-01-2020.

${ }^{1}$ Dra. Académica e investigadora del Programa Sectores Productivos, Competitividad y Desarrollo de la Escuela de Economía, Universidad Nacional, Costa Rica. Correo electrónico shirley.benavides.vindas@una.ac.cr ORCID: https://orcid.org/0000-0001-8383-397X

Shirley Benavides Vindas

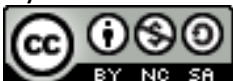

Revista Economía y Sociedad by Universidad Nacional is licensed under a CreativeCommons Reconocimiento-NoComercial- 
agregado a la producción interna de un 6,3 \%, aunque por el potencial que el país tiene, por la variedad de recursos y territorios, este aporte podría ser mucho mayor.

Palabras claves: Sector productivo; Valor agregado; Política pública; PIB Turístico; Matriz Insumo Producto.

\begin{abstract}
In 2005, the last article related to the contribution of tourism to the Costa Rican economy was published, therefore, due to the importance of this activity for the country; it has been considered to update and expand the analysis of its results, over a decade after the first publication. The data was gathered from official sources, both national and international; which guarantees the reliability of the information generated. The international context is presented as well as the behavior of a series of variables that makes it possible to determine the contribution to the Costa Rican economy. The two activities that contribute the most to tourism and the economy in general are the "characteristic products of tourism" and "tourism-related services"; generated mostly by microenterprises, due to the risks they face because of their commercial vulnerability; moreover, the largest producer of revenues is the one related to "accommodation"; and secondly, "other industries related to tourism"; these last ones enable more and better commodity chains. According to the Central Bank of Costa Rica, the tourism GDP for 2016, the latest data available, was 1554928 million of colons [corresponding to US\$ 2 712,6 million], representing a value added of 6,3\% for domestic production; although, based on the country's potential and due to the variety of resources and territories, this contribution could be much greater.
\end{abstract}

Keywords: Productive sector; Value added; Public policy; Tourist GDP; Product Input Matrix

\title{
Resumo
}

Em 2005, foi publicado o último artigo relacionado com a contribuição do turismo para a economia da Costa Rica. Por esse motivo e devido à importância dessa atividade para o país, sua atualização e ampliação da análise dos resultados gerados foram consideradas, mais de uma década após a primeira publicação. Trabalhou-se com dados de fontes oficiais, nacionais e internacionais, que garantam a confiabilidade das 
informações geradas, para a análise nesses dois níveis. São apresentados um contexto internacional e o comportamento de uma série de variáveis que permitem determinar a contribuição para a economia da Costa Rica. As duas atividades que mais contribuem para o turismo e a economia em geral são: "produtos característicos do turismo" e "serviços ligados ao turismo". Elas são geradas, em grande parte, por microempresas, com os riscos que isso implica porque são as mais vulneráveis no parque empresarial. O maior produtor e gerador de valor está relacionado à "hospedagem" e, em segundo lugar, "outras indústrias associadas ao turismo", que possibilitam mais e melhores cadeias produtivas. De acordo com o Banco Central da Costa Rica e segundo os dados mais recentes, o PIB do turismo em 2016 foi de 1554928 milhões de colones [correspondentes a US\$ 2.712,6 milhões], representando um valor agregado à produção interna de 6,3\%; entretanto, essa contribuição poderia ser muito maior devido ao potencial do país proveniente da variedade de recursos e territórios que detém.

Palavras-chaves: Setor produtivo; Valor agregado; Política pública; PIB turístico; Matriz de insumo-produto

\section{Introducción}

El turismo ha experimentado un continuo crecimiento y una profunda diversificación, hasta convertirse en una de las actividades económicas que crecen con mayor rapidez en el mundo; lo que lo ha vinculado de manera directa al desarrollo y, por ende, lo ha convertido en un motor clave del progreso socioeconómico. Costa Rica puede aprovechar esos resultados, si optimiza todos los recursos con que cuenta en todo su territorio y mejora las posibilidades de desenvolvimiento de su parque empresarial.

Por la importancia de esta actividad económica, en el año 2005 se publicó el último artículo relacionado con el aporte del turismo a la economía costarricense, por ello, se ha considerado su actualización y ampliación del análisis de los resultados generados, más de una década después de la primera publicación.

Se trabajó con datos de fuentes oficiales como la Organización Mundial del Turismo (OMT); el Instituto Costarricense de Turismo (ICT); Ministerio de Comercio Exterior (COMEX); el Banco Central de Costa Rica (BCCR), mediante la Cuenta Satélite de Turismo y el Cuadro de Oferta y Utilización 2016 (última versión), y las encuestas de hogares del Instituto Nacional de Estadísticas y Censos (INEC). Orienta este artículo el propósito de generar información veraz que permita

\footnotetext{
Shirley Benavides Vindas

(c) (1) 8 (2)

Revista Economía y Sociedad by Universidad Nacional is licensed under a CreativeCommons Reconocimiento-NoComercial- 
aproximarse, hasta donde los datos lo han permitido, al aporte de este sector a la economía costarricense.

El texto se ha organizado con un primer apartado que expone al sector turístico a nivel mundial, su comportamiento y tendencias; así como su aporte para alcanzar metas relacionadas con los objetivos del milenio, particularmente de los objetivos 8, 12 y 14 . Posteriormente se presenta la información relacionada con la contribución a la economía costarricense, tomando en cuenta las principales variables: generación de divisas; aporte a las exportaciones, a la inversión directa extranjera (IDE), al empleo; así como la relación de su contribución versus otros productos generados. En el apartado final, se incluyen las principales conclusiones que surgen del proceso analítico respectivo.

\section{El turismo en el mundo}

Uno de los sectores más dinámicos y versátiles de las economías es, sin ninguna duda, el turismo; este trae consigo mayor inversión, divisas, empleos (tanto directos como indirectos), encadenamientos productivos con otros sectores, ingresos fiscales; todo ello, gestionado de manera adecuada, puede impactar de manera positiva en el bienestar y desarrollo de las sociedades en las cuales se lleva a cabo este tipo de actividades. La misma OMT, ha señalado:

Durante décadas, el turismo ha experimentado un continuo crecimiento y una profunda diversificación, hasta convertirse en uno de los sectores económicos que crecen con mayor rapidez en el mundo. El turismo mundial guarda una estrecha relación con el desarrollo y se inscriben en él un número creciente de nuevos destinos. Esta dinámica ha convertido al turismo en un motor clave del progreso socioeconómico.

Hoy en día, el volumen de negocio del turismo iguala o incluso supera al de las exportaciones de petróleo, productos alimentarios o automóviles. El turismo se ha convertido en uno de los principales actores de comercio internacional y representa al mismo tiempo una de las principales fuentes de ingresos de numerosos países en desarrollo. (OMT, 2018a, párr. 2-3)

Se ha convertido en una actividad tan estratégica para el desarrollo, que incluso en la reunión de jefes de Estado realizada en la cumbre en Nueva York en setiembre del 2015, en el marco de la Asamblea General de las Naciones Unidas, para optar por la Agenda 2030 para el Desarrollo Sostenible, el turismo, entre otros sectores y actividades, se incluyó como parte de las estrategias, para alcanzar metas relacionadas con los objetivos del milenio, particularmente de los objetivos 8, 12 y 14. En relación con ello se estableció: 
Promover el crecimiento económico sostenido, inclusivo y sostenible, el empleo productivo y el trabajo decente para todos. El turismo es una de las fuerzas motrices del crecimiento económico mundial y actualmente proporciona en todo el mundo 1 de cada 11 puestos de trabajo. Dando acceso a oportunidades de trabajo decente en el sector turismo. La sociedad, y en particular los jóvenes y las mujeres, pueden beneficiarse de la mejora de las destrezas y el desarrollo profesional. La contribución del sector a la creación de empleo se reconoce en la meta 8.9: “Para 2030 elaborar y poner en práctica políticas encaminadas a promover un turismo sostenible que cree puestos de trabajo y promueva la cultura y los productos locales".

Garantizar modalidades de consumo y producción sostenible. Un sector turístico que adopta prácticas de consumo y producción sostenibles puede tener un papel significativo a la hora de acelerar la transformación global hacia la sostenibilidad. Para ello se señala en la meta 12.b del objetivo 12, es imprescindible. "Elaborar y aplicar instrumentos que permitan seguir de cerca los efectos en el desarrollo sostenible con miras a lograr un turismo sostenible que cree puestos de trabajo y promueva la cultura y los productos locales". El programa de turismo sostenible del marco decenal de programas sobre modalidades de consumo y producción sostenibles aspira a desarrollar esas prácticas del programa de desarrollo sostenible, que incluirán iniciativas de uso eficiente de los recursos que redundarán en unos mejores resultados económicos, sociales y ambientales.

Conservar y utilizar en forma sostenible los océanos, los mares y los recursos marinos para el desarrollo sostenible. El turismo costero y marítimo, el mayor segmento turístico, especialmente para los pequeños Estados insulares en desarrollo (PEID), depende de unos ecosistemas marinos saludables. El desarrollo del turismo debe formar parte de una ordenación integrada de las zonas costeras a fin de ayudar a conservar y preservar unos ecosistemas frágiles y servir de vehículo para promover la economía azul, en consonancia con la meta 14.7: «De aquí a 2030, aumentar los beneficios económicos que los pequeños Estados insulares en desarrollo y los países menos adelantados obtienen del uso sostenible de los recursos marinos, en particular mediante la gestión sostenible de la pesca, la acuicultura y el turismo». (OMT, 2018b, párr. 1-5)

Lo anterior denota la importancia estratégica sobre el desarrollo que tienen las diversas actividades relacionadas directamente con el turismo y con aquellas que se pueden encadenar de alguna manera; el valor agregado al desarrollo es relevante desde todo punto de vista, según la OMT $(\underline{2018 c})$ :

El turismo es uno de los principales motores del comercio y de la prosperidad en el mundo. La atenuación de la pobreza es uno de los mayores retos globales. A pesar del momento turbulento que atraviesa la economía mundial, estas verdades son difíciles

Shirley Benavides Vindas 
de cambiar. Enfocar el poder de creación de riqueza del turismo hacia las personas más necesitadas es por tanto una tarea inmensa y una extraordinaria oportunidad. (párr. 1) ... aporta el 5\% del PIB mundial y representa el 6\% de las exportaciones de servicios mundiales. Es además el cuarto sector exportador, después del petróleo, los productos químicos y la automoción. El turismo representa 235 millones de empleos, o sea uno de cada doce empleos en el mundo." (párr.2).

Para lograr adecuados niveles de desarrollo, debe estimularse el crecimiento sostenido de los sectores productivos, con el propósito de posibilitar incrementos en la productividad nacional y mejorar la redistribución. Todo ello acompañado de una mejor calidad y calificación del recurso humano, esto apoyado de la institucionalidad pública; para impulsar la innovación y la transferencia de tecnología y conocimiento científico, a los sectores más vulnerables y de mayor potencial. Se fortalecen, así, las condiciones para que dicho crecimiento sea socializado en pro de la mejora del bienestar de la sociedad.

El turismo posibilita el logro de estas metas de desarrollo, por las características de generación de condiciones favorables y de encadenamientos para impulsar la economía local, regional y nacional, como se ha venido demostrando, según los datos mundiales. Esto, mediando las estrategias de crecimiento sostenibles en la creación de riqueza y progreso de los territorios; el adecuado uso de fuentes de energía no renovables; ciclos productivos amigables con el ambiente y el compromiso de generar una huella ecológica positiva para el planeta, como lo ha impulsado en los objetivos del milenio.

Según la OMT, el comportamiento del turismo a nivel mundial ha venido presentando los siguientes resultados representativos de la dinámica del sector.

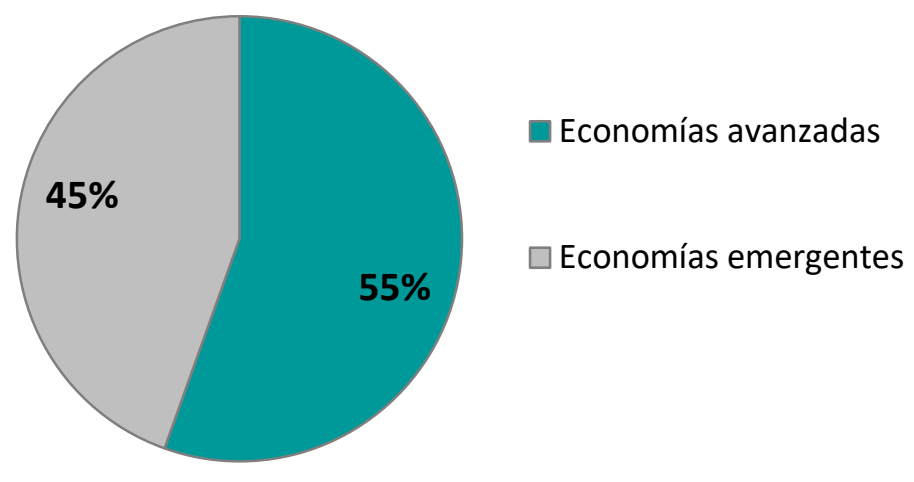

Figura 1. Cuota de mercado de llegada de turistas internacionales según tipo de economía en el mundo al 2017 (valores porcentuales). Elaboración propia con datos del OMT (2018d). 
Como se aprecia en la Figura 1, la mayoría del flujo de los turistas internacionales se dirige a los países de economías avanzadas (55\%); el resto confluye en las economías emergentes, las cuales se han caracterizado por su heterogeneidad, pese a ello presentan características en común, tales como la dinamización del proceso de industrialización, baja renta per cápita con alto crecimiento económico, el sector exterior en aumento por sus exportaciones (por ejemplo India y China); todo ello les da atractivos para inversionistas que buscan mercados rentables, compuestos por una importante parte de la población mundial, favoreciendo así el consumo, por el potencial de crecimiento económico.

Como complemento a lo anterior, y de manera más regional el OMT ha generado los datos de las llegadas de turistas internacionales, según región, estos se presentan en la Figura 2.

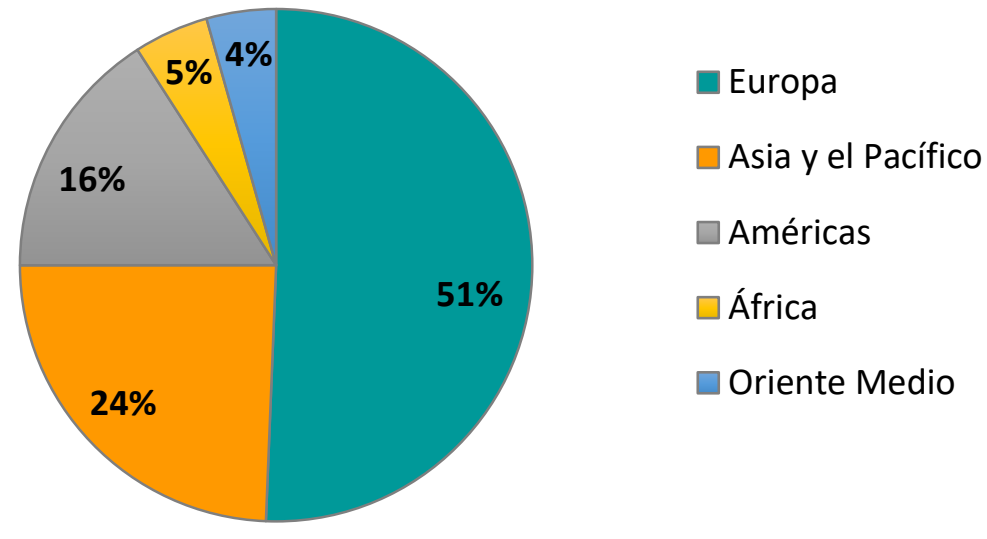

Figura 2. Cuota de mercado de llegada de turistas internacionales en el mundo según región al 2017 (valores porcentuales). Elaboración propia con datos del OMT (2018d).

Europa sigue siendo el destino más gustado por los turistas internacionales, ofrece una serie de actividades y productos culturales, históricos, de paisaje e incluso de negocios que permiten una elección relevante para el consumo; seguido por Asia y el Pacífico, que se caracterizan por ser de las economías emergentes e importantes del mundo. El continente americano tiene la posición tercera, por debajo de Europa y Asia; pese a ello, no es despreciable para países como los nuestros el nivel de elección, con el potencial que la región tiene en cantidad de territorio y en biodiversidad que posee, lo cual le facilita una serie de productos turísticos que traen un segmento importante de visitantes del extranjero.

Por su parte, las principales variaciones de llegadas de turistas se presentan en Figura $\underline{3}$, según datos de la OTM: 


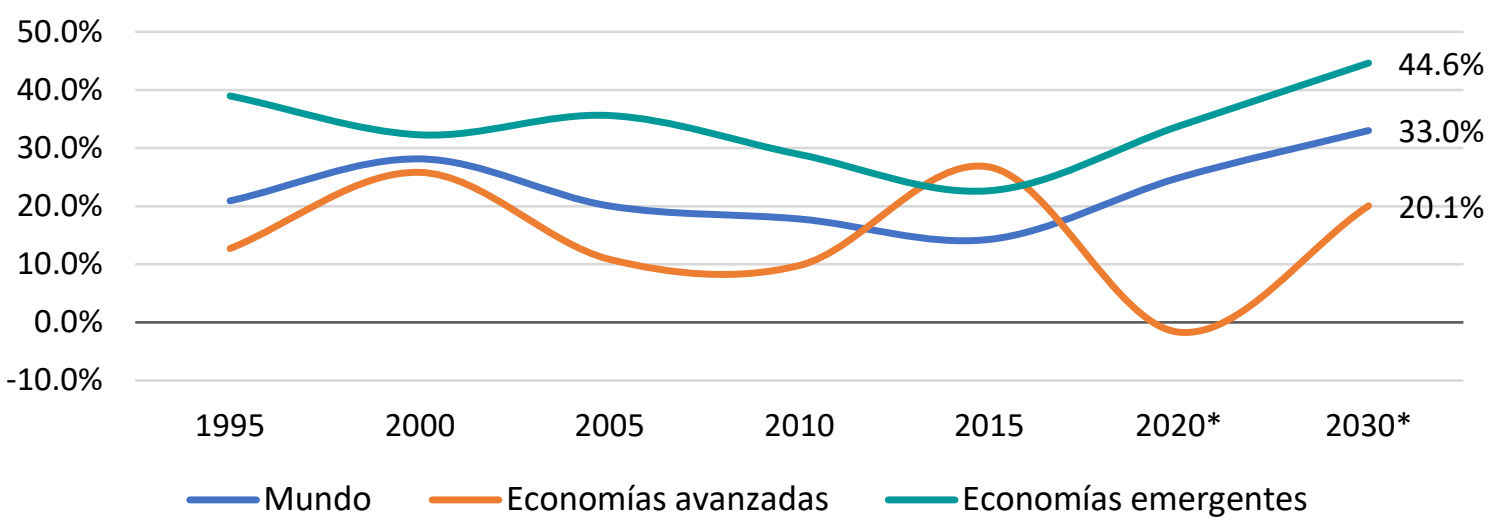

Figura 3. Variación de llegadas de turistas internacionales según tipo de economía en el periodo 1995-2030 en el mundo (valores porcentuales). Fuente: elaboración propia con datos del OMT (2017). Nota: Las variaciones respectivas a los años 2020 y 2030 son proyecciones

Se torna interesante el comportamiento de la visitación a nivel general y a los países emergentes versus el de las economías avanzadas; ello podría valorarse como una oportunidad para la región de Latinoamérica en general, y particularmente, para Costa Rica, mediante estrategias adecuadamente dirigidas a segmentos de mercados interesados en la diversidad de oferta de servicios turísticos que el país y a la región les ofrecen.

Como complemento a lo anterior, se presenta en la Figura 4 , el comportamiento de la llegada de turistas internacionales por región desde 1995 y proyecciones al 2020 y 2030, según datos de la OMT.

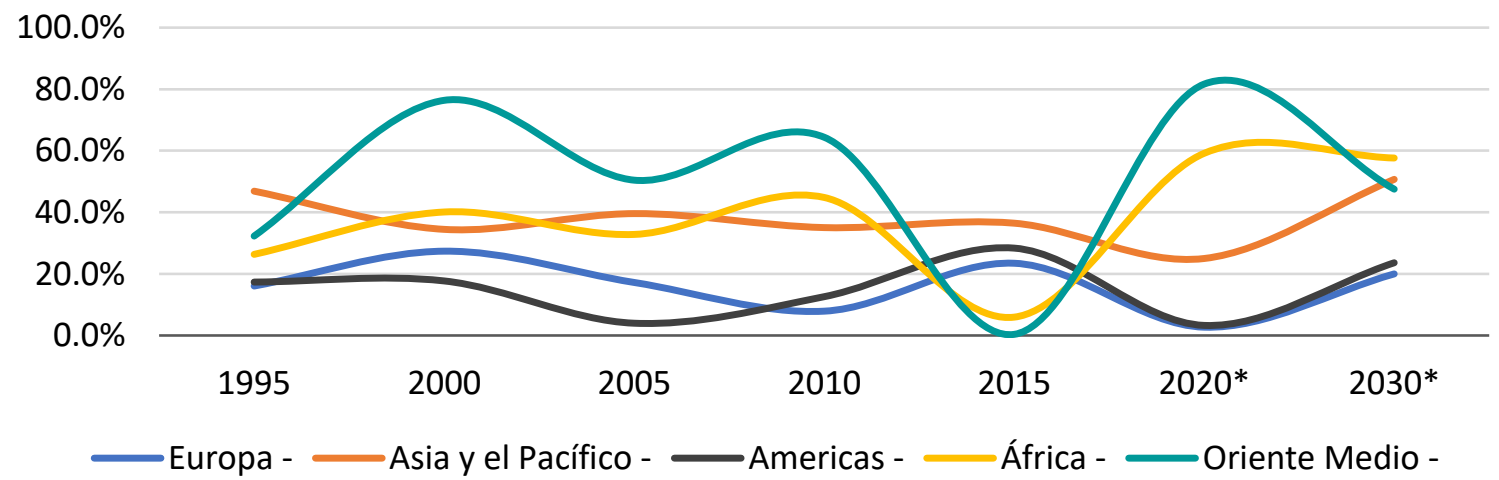

Figura 4. Variación de llegadas de turistas internacionales según región en el mundo en el periodo 1995-2030. (valores porcentuales). Fuente: elaboración propia con datos de la OMT (2017). 
La región más estable en visitación es Asia y el Pacífico, las otras presentan comportamientos más irregulares; en el caso de las Américas se dieron oscilaciones menos fuertes que en África u Oriente Medio, pero con una clara tendencia a la baja para el 2020; aspecto que debería llamar la atención en el marco de las estrategias del turístico de la región en general y de Costa Rica de manera particular, para no generar un impacto negativo en la dinámica de este sector y revertir la tendencia a la baja.

Por otra parte, en la Figura $\underline{5}$, se incluye el comportamiento de las llegadas de turistas internacionales, tomando en cuenta el tipo de economía, según la OMT

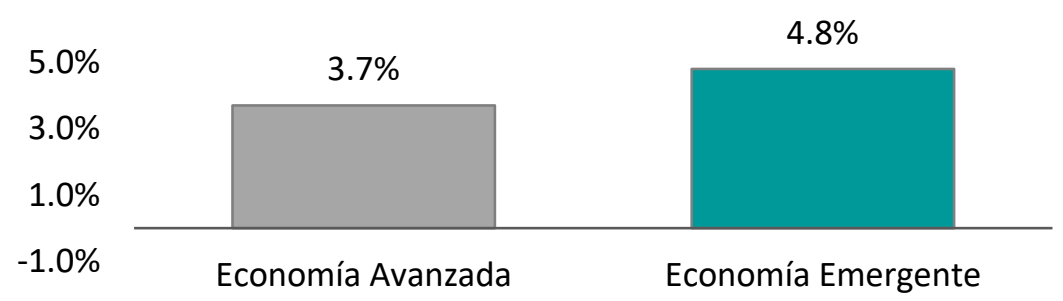

Figura 5. Crecimiento promedio de llegadas de turistas internacionales según el tipo de economía en el mundo en el periodo 2005-2017 (valores porcentuales). Fuente: elaboración propia con datos de la OMT (2018d).

Resulta interesante observar que las economías emergentes presentan una leve inclinación en el gusto y preferencias de turistas que se desplazan a nivel internacional. Algunos de los países que se han señalado con esta característica son: Argentina, Brasil, Chile, China, Colombia, India, Malasia, Corea, Marruecos, Perú, República Checa, Egipto, Filipinas, Hungría, Indonesia, México, Tailandia, Taiwán, Rusia, Pakistán, Polonia, Sudáfrica, Turquía. Este tipo de países se encuentra en transición, saliendo del subdesarrollo, debido al aprovechamiento y gestión de sus recursos naturales y a la deslocalizacion industrial, mediante la adaptación de industrias de los países más avanzados, a los cuales les ofrece costes productivos más bajos y facilidades empresariales; este tipo de costes pueden generar una competitividad espurea y, por ende, un desarrollo sostenido.

En cuanto al crecimiento de la llegada de turístias internacionales según la región del mundo, se presenta en la Figura $\underline{6}$ lo correspondiente al comportamiento de los últimos años.

Lo exótico de su cultura, su historia y la gastronomía de Asia y el Pacífico parece ser lo que ha generado una mayor atracción para el turismo internacional, es la región del mundo que presenta un crecimiento porcentualmente superior al resto. América y Europa muestran las tasas menores de incremento. Este elemento es relevante al momento de generar ofertas turísticas, para determinar las características de la competencia en los mercados internacionales turísticos.

Shirley Benavides Vindas

Revista Economía y Sociedad by Universidad Nacional is licensed under a CreativeCommons Reconocimiento-NoComercial- 
Por su parte, se presenta en la Figura $\underline{7}$, la participación relativa de América Central en comparación con los principales mercados, según el total de visitantes en el periodo 2012 - 2017:

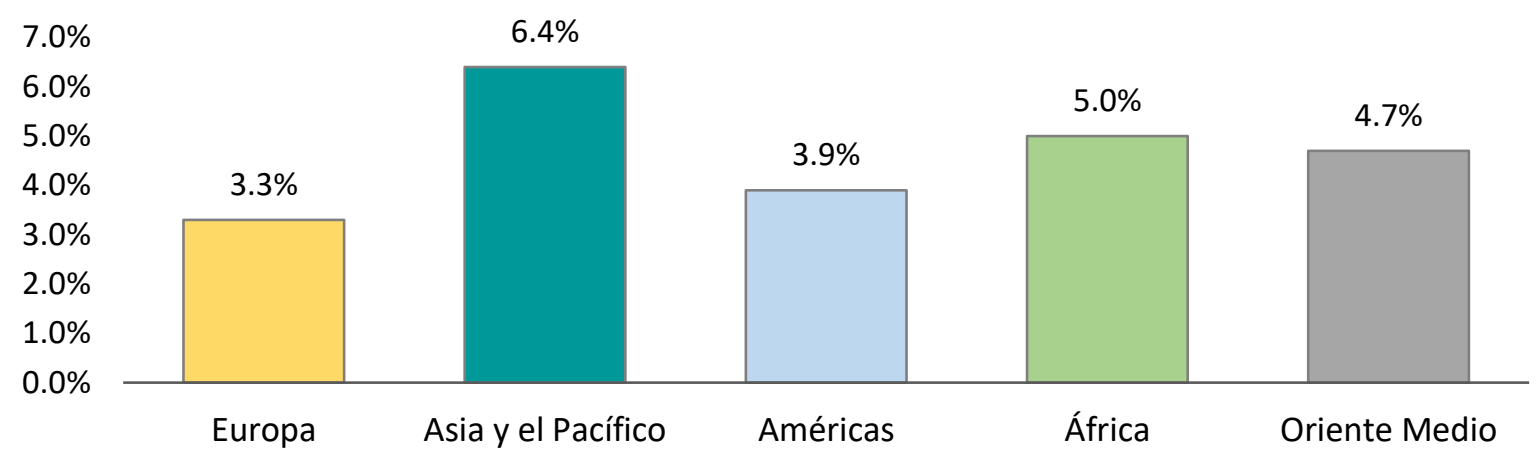

Figura 6. Crecimiento medio anual de llegadas de turistas internacionales según región en el mundo en el periodo 2005-2017 (valores porcentuales). Fuente: elaboración propia con datos de la OMT (2018d).

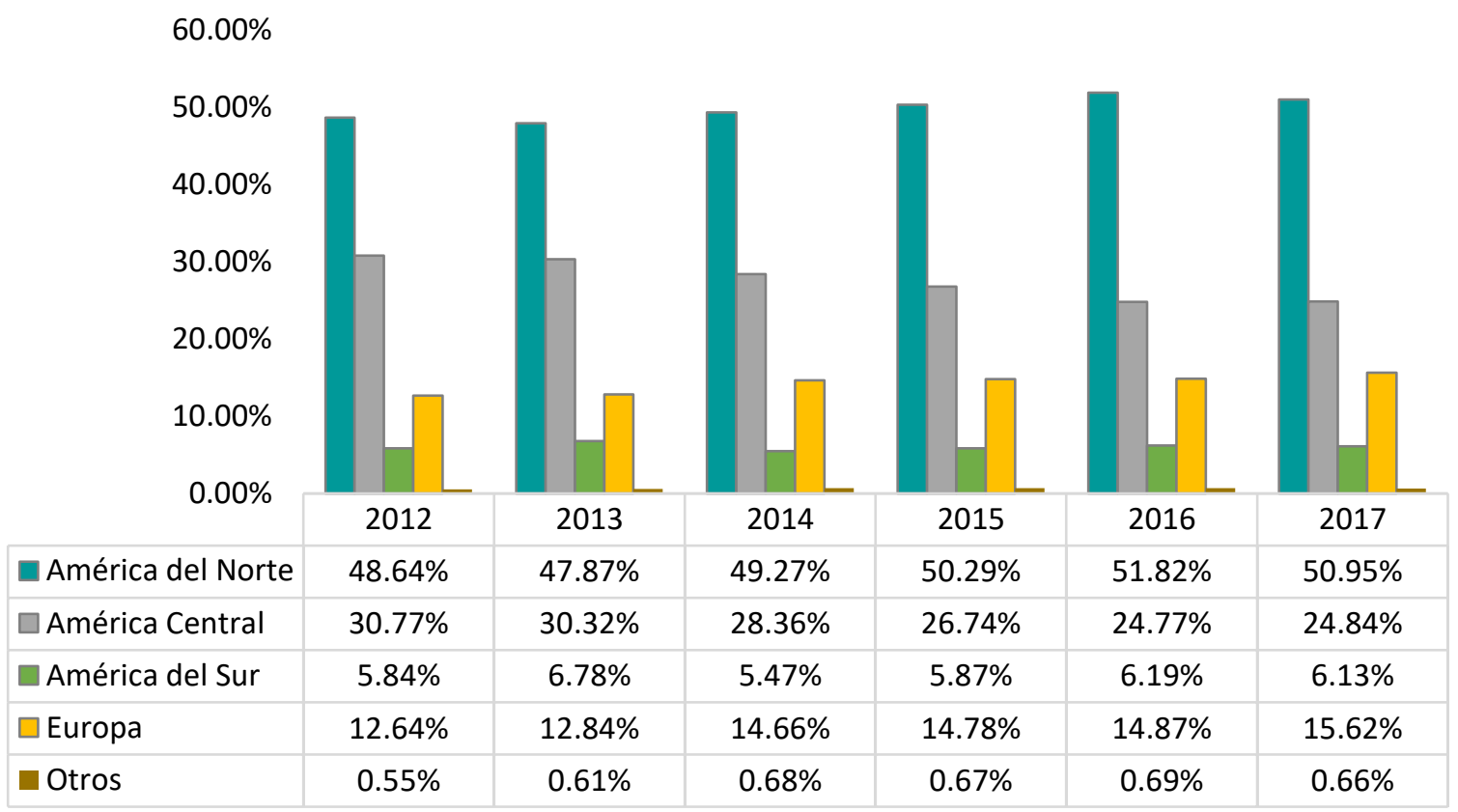

Figura 7. América Central: participación relativa en comparación con los principales mercados, según el total de visitantes para el periodo 2012 - 2017 (valores porcentuales). Fuente: elaboración propia con datos ICT (2017b).

América Central ocupa el segundo lugar como destino turístico de quienes visitan las Américas, ello podría ser el resultado de su ubicación geográfica, ya que sirve de puente de comunicación e 
intercambio con el mercado de Estados Unidos, el cual es el principal mercado turístico del continente; pero, además, la oferta turística de productos que posee la región de América Central es atractiva, relacionada con la diversidad ecológica, las playas y lo cultural.

En el caso de Costa Rica se puede aprovechar su posición geográfica, su estabilidad política y su oferta diversificada de productos y servicios turísticos, tales como: recursos naturales atractivos -flora y fauna-, riqueza y diversidad ecológica, que converge con los micro climas, que posibilitan condiciones fisiográficas y topográficas de la región, además, la flora es prototipo de los ricos y variados ecosistemas tropicales centroamericanos; todo ello es muy atractivo para el sujeto consumidor internacional, situación que coloca al país con una ventaja competitiva.

En la Figura $\underline{8}$, se presenta el comportamiento de las llegadas de turistas internacionales a las diversas regiones de América.

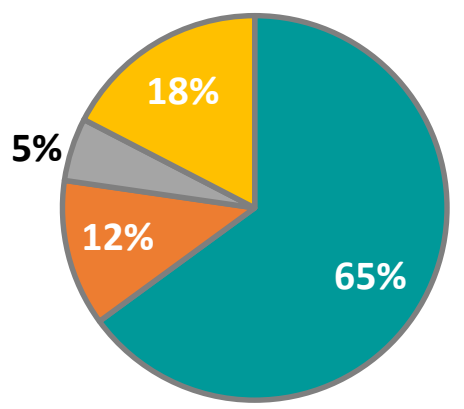

América del Norte

El Caribe

América Central

América del Sur

Figura 8. Cuota de mercado de llegada de turistas internacionales según región de América al 2017 (valores porcentuales). Fuente: elaboración propia con datos de la OMT (2018d).

América del Norte es la que presenta mayor demanda por parte de turistas internacionales con un $65 \%$ del total de la demanda del continente, seguida por América del Sur, pero con una distancia porcentual muy relevante, apenas del $18 \%$. El caso de la Centroamérica "tan pequeña, pero tan grande", apenas suma un $5 \%$ y con los diversos conflictos políticos, sociales y económicos que presenta, lo que hace que se perciba como territorio inseguro. Esa cifra podría disminuir, con los efectos negativas sobre la dinámica del sector y del personal que depende de él para mejorar sus condiciones de vida, como lo es el caso de Costa Rica, que se analizará en el apartado siguiente.

Por su parte, en la Figura $\underline{9}$ se presenta la variación del comportamiento de los turistas internacionales según la región en el continente americano es el siguiente según la OMT. 


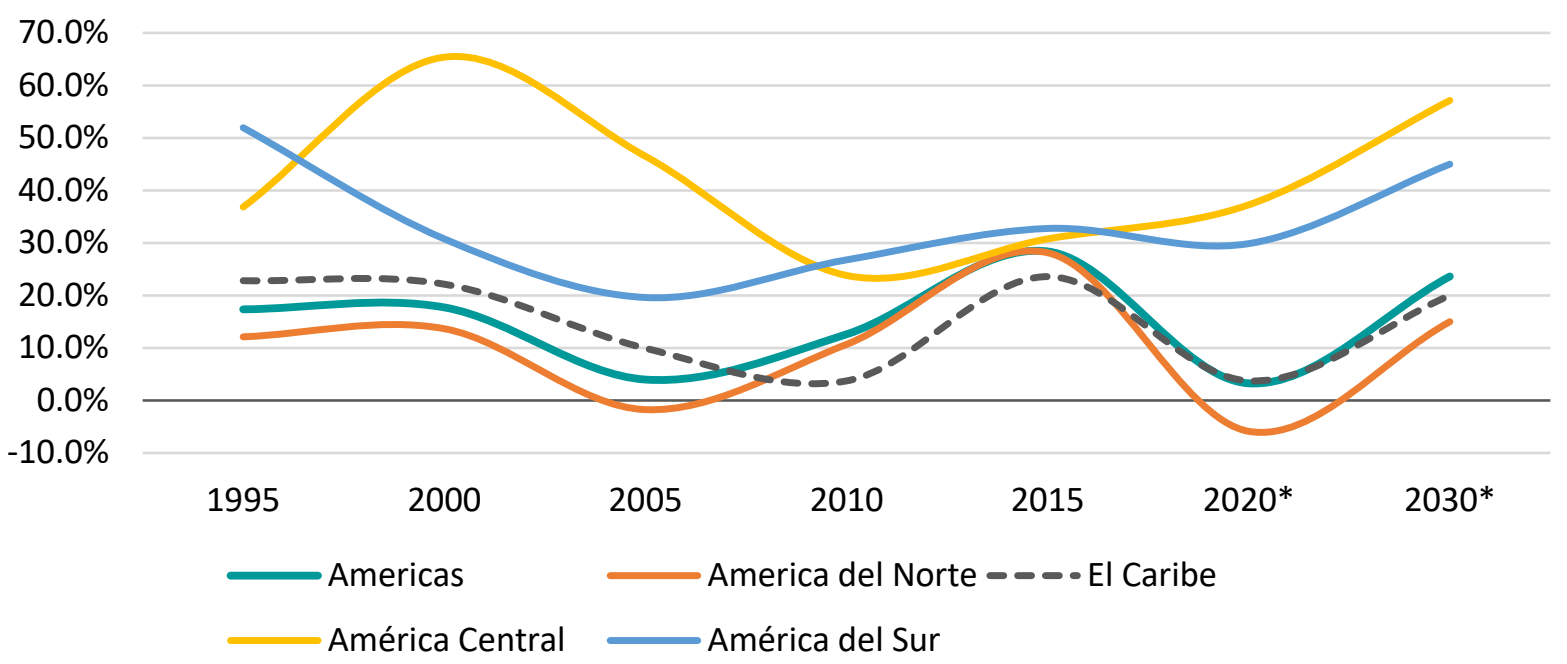

Figura 9. Variación de llegadas de turistas internacionales según región de América en el periodo 1995-2030 (valores porcentuales). Fuente: elaboración propia con datos de la OMT (2017).

Como se refleja en la Figura $\underline{9}$, América Central es la región que presenta mayores tasas de variación, seguida por América del Sur; ambas con cambios importantes proyectados para los próximos años; aspecto a considerar al momento de generar las ofertas turísticas de estas regiones, incluso para determinar las demandas que compiten con ellas. Por su parte, orienta el desarrollo turístico relacionándolo con el número de arribos de turistas internacionales, la generación de divisas, la inversión nacional y extranjera y empleo, tanto directo como indirecto asociado a este sector.

\section{El turismo en la economía costarricense}

Para el análisis de la situación del turismo en Costa Rica, se han seleccionado una serie de variables que permitan reflejar, de manera más precisa, el verdadero aporte del sector turístico a la economía del país, para lo cual se tienen en cuenta aspectos relacionados con las tasas de comportamiento que se han venido presentando; su contribución a las fuentes de divisas de la economía, ingresos e inversión directa; comparación con las exportaciones; efecto en el empleo; entre otros temas.

Costa Rica posee una oferta de productos turísticos amplia y variada; cuenta con un sistema de parques nacionales y áreas protegidas que cubren alrededor de un $25 \%$ del territorio nacional, en los cuales se encuentran una gran variedad de flora y fauna, se estima que este alberga un $5 \%$ de la biodiversidad del mundo en menos del 0,1\% de la masa terrestre del planeta; además, posee playas tanto en el océano Pacífico como en el Mar Caribe, todo ello permite contar con una 
amplia oferta de actividades y servicios turísticos, para diferentes segmentos del turismo, tanto local como internacional.

Por otra parte, la actividad turística provee más ingreso por divisas que las exportaciones de los cultivos tradicionales juntos, como el banano, piña y café. Según el Banco Central de Costa Rica, el PIB Turístico es de 1554 928,75 millones de colones para el año 2016, último dato brindado por dicha institución.

En relación con la variación porcentual del turismo y de otras fuentes generadoras de divisas en los últimos años, según el ICT y el BCCR, su comportamiento ha sido el que se muestra en la Tabla $\underline{1}$ y la Figura 10 , se incluyen ambos con el propósito de clarificar mejor esta información, por su relevancia:

Tabla 1

Costa Rica: Variación porcentual del turismo y otras fuentes generadoras de divisas en el periodo 2004-2017 (Valores porcentuales)

\begin{tabular}{cccccc}
\hline Año & Turismo & Café & Banano & Piña & $\begin{array}{c}\text { Productos } \\
\text { farmacéuticos } \\
\text { y medicinales }\end{array}$ \\
\hline 2004 & $12,8 \%$ & $2,1 \%$ & $-1,1 \%$ & $29,3 \%$ & $12,9 \%$ \\
2005 & $15,2 \%$ & $17,8 \%$ & $-12,2 \%$ & $26,6 \%$ & $0,1 \%$ \\
2006 & $3,0 \%$ & $-3,0 \%$ & $30,2 \%$ & $33,4 \%$ & $8,4 \%$ \\
2007 & $18,5 \%$ & $11,6 \%$ & $6,2 \%$ & $12,0 \%$ & $7,8 \%$ \\
2008 & $13,6 \%$ & $21,1 \%$ & $2,4 \%$ & $18,3 \%$ & $8,3 \%$ \\
2009 & $-21,1 \%$ & $-23,9 \%$ & $-9,8 \%$ & $4,4 \%$ & $3,5 \%$ \\
2010 & $11,0 \%$ & $10,9 \%$ & $12,8 \%$ & $12,0 \%$ & $-14,0 \%$ \\
2011 & $7,9 \%$ & $45,6 \%$ & $7,0 \%$ & $6,5 \%$ & $-0,8 \%$ \\
2012 & $4,5 \%$ & $10,0 \%$ & $8,5 \%$ & $7,7 \%$ & $-52,4 \%$ \\
2013 & $16,0 \%$ & $-26,8 \%$ & $3,9 \%$ & $5,4 \%$ & $-0,7 \%$ \\
2014 & $2,3 \%$ & $-8,2 \%$ & $6,9 \%$ & $8,8 \%$ & $156,1 \%$ \\
2015 & $9,1 \%$ & $10,3 \%$ & $-8,1 \%$ & $-7,5 \%$ & $10,4 \%$ \\
2016 & $13,8 \%$ & $0,9 \%$ & $19,2 \%$ & $10,1 \%$ & $4,6 \%$ \\
2017 & $4,2 \%$ & $-1,1 \%$ & $4,8 \%$ & $8,3 \%$ & $5,3 \%$ \\
\hline
\end{tabular}

Fuente: elaboración propia con datos de ICT y BCCR (s. f). Nota Es necesario aclarar que, según el Organismo Mundial del Turismo (OMT), no se incluye el gasto realizado por excursionistas o cruceristas, por no pernoctar en el territorio nacional y permanecer en él 12 horas o menos. 


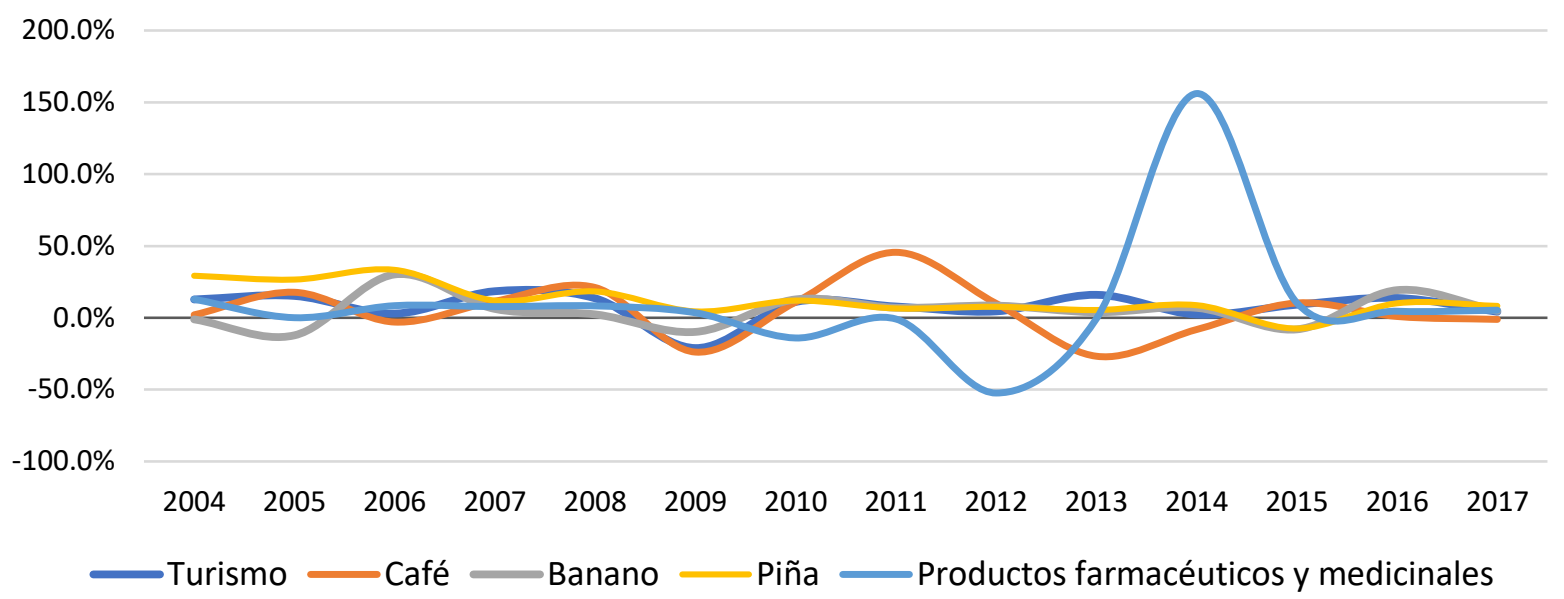

Figura 10. Costa Rica: Variación porcentual del turismo y otras fuentes generadoras de divisas en el periodo 2004-2017 (valores porcentuales). Fuente: elaboración propia con datos de Instituto Costarricense de Turismo y Banco Central de Costa Rica ( $\underline{s . f .}$.).

Como se puede observar, los aportes relativos a la generación de divisas por parte de los principales productos de exportación del país han presentado un comportamiento bastante variado, pese a ello, el turismo es el que evidencia cambios menos abruptos, o sea, se ha mantenido en una franja más limitada, pero con mayor aporte sostenido que otros productos que presentan picos relevantes en dicha generación, como lo es el caso de los farmacéuticos y medicinales, que han pasado de una tasa de $-52,45$ a 156,1 \% de participación en los 13 años estudiados.

En la Figura 11 se presenta el ingreso de divisas para Costa Rica por concepto de turismo como proporción de las exportaciones 2003-2017.

Como se puede observar, en los últimos catorce años se ha presentado un incremento porcentual en el ingreso de divisas por concepto de turismo, en relación con el resto de las exportaciones del país, particularmente, a partir del 2011, comportamiento que es coherente con la tendencia mundial, según la organización Mundial del Turismo (OMT, 2011). Las llegadas de turistas internacionales crecieron casi un $5 \%$ durante los primeros meses de 2011, consolidándose así el repunte del $7 \%$ registrado en 2010. Según la actualización provisional publicada en abril del barómetro OMT del Turismo Mundial, el crecimiento fue positivo en todas las regiones y subregiones del mundo durante enero y febrero de 2011 . Pese a una disminución del $2 \%$ para el 2012 y 2014, la tasa se ha mantenido en crecimiento de manera bastante constante, para llegar al 2017 a un aporte del 35 \% a las divisas que ingresan al país por exportaciones. 


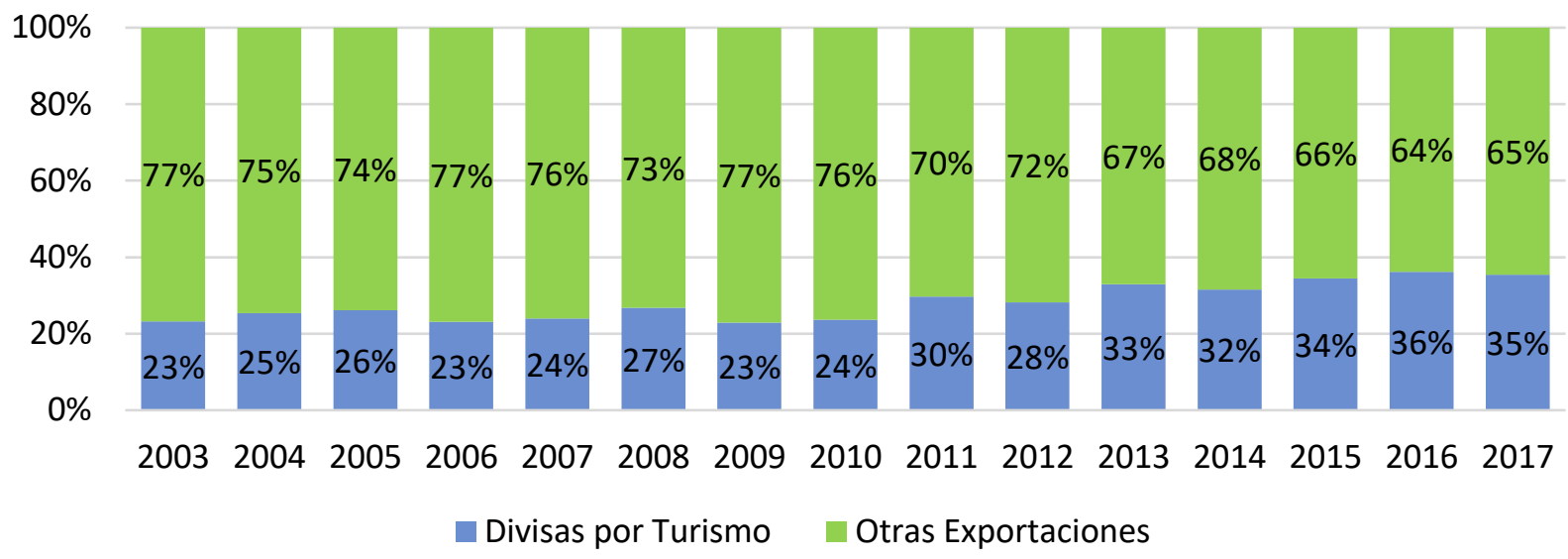

Figura 11. Costa Rica: Ingreso de divisas por concepto de turismo como proporción del total de exportaciones en el periodo 2003-2017 (valores porcentuales). Fuente: elaboración propia con datos de Instituto Costarricense de Turismo y Banco Central de Costa Rica (s. f.).

Como complemento a lo anterior, en la Tabla $2 \underline{2}$ se presenta el saldo y su variación neta en relación con el ingreso al país de divisas y su egreso, para la actividad de turismo:

Tabla 2

Costa Rica: Ingreso y egreso de divisas por concepto de turismo, en el periodo 2003 - 2017. (En USD millones y valores porcentuales)

\begin{tabular}{ccccc}
\hline Año & Ingreso de divisas & Egreso de divisas & Saldo & Variación Saldo (\%) \\
\hline 2003 & 1416,0 & 348,6 & 1067,4 & - \\
2004 & 1596,6 & 400,5 & 1196,1 & $12,1 \%$ \\
2005 & 1839,9 & 463,4 & 1376,5 & $15,1 \%$ \\
2006 & 1894,3 & 479,0 & 1415,3 & $2,8 \%$ \\
2007 & 2244,7 & 625,4 & 1619,3 & $14,4 \%$ \\
2008 & 2549,0 & 586,3 & 1962,7 & $21,2 \%$ \\
2009 & 2011,6 & 363,1 & 1648,5 & $-16,0 \%$ \\
2010 & 2233,5 & 418,0 & 1815,5 & $10,1 \%$ \\
2011 & 2409,2 & 400,1 & 2009,1 & $10,7 \%$ \\
2012 & 2517,2 & 422,0 & 2095,2 & $4,3 \%$ \\
2013 & 2919,4 & 424,8 & 2494,6 & $19,1 \%$ \\
2014 & 2986,7 & 450,1 & 2536,6 & $1,7 \%$ \\
2015 & 3258,9 & 690,1 & 2568,8 & $1,3 \%$ \\
2016 & 3708,0 & 819,2 & 2888,8 & $12,5 \%$ \\
2017 & 3864,1 & 907,4 & 2956,7 & $2,4 \%$ \\
\hline
\end{tabular}

Fuente: elaboración propia con datos Instituto Costarricense de Turismo y Banco Central de Costa Rica (s. f.). 
Como se puede observar en la Tabla 2 , con excepción del 2009, año en que en la industria del sector turismo se afectó por la crisis financiera mundial y las medidas que los diversos países tomaron ante la pandemia de influenza AH1N1 (aspectos que afectaron la demanda global); el saldo se ha mantenido en positivo, con excepción del 2009, aunque con variaciones porcentuales, que van desde el mayor porcentaje de un 19,1 \% en el 2013 al menor con un 1,3 \% en el 2015. Este comportamiento positivo, pese a su variabilidad, podría ser el resultado de los diversos esfuerzos promocionales y la participación en ferias que el ICT impulsa internacionalmente, sumado a el aumento de llegadas de más aerolíneas al país, lo que facilita el ingreso de visitantes, incluso con vuelos directos desde Europa. Pese a ello, la variación del saldo podría incrementarse, por todas las potencialidades y oferta turística con que cuenta Costa Rica, para ello se requiere una serie de esfuerzos institucionales en las diversas regiones del país de manera mucho más constante y dinámica.

Otro aspecto relevante reflejado en la economía del país es el relacionado con la importancia de la inversión extranjera directa (IED), para potenciar el desarrollo de los países, especialmente los de menor desarrollo relativo, como es el caso de Costa Rica; esto, a través de su contribución a dinamizar los diversos sectores productivos; ello posibilita mejorar los niveles de crecimiento, los cuales pueden ser sostenidos en el largo plazo, si se logra anclar a una política de desarrollo estratégica; además de la formación de capital físico, también posibilita la transferencia tecnológica y know how y la calificación del recurso humano, lo cual se puede orientar a las pequeñas y medianas empresas, que conforman gran parte del parque empresarial.

En la Figura 12 se presenta la relación con la IED que aportan los diversos sectores productivos del país, entre los cuales se encuentra el turismo.

La industria manufacturera es la que ha captado mayor aporte al rubro de la IED, históricamente ha sido así y los últimos 15 años no es la excepción, pese a su variabilidad en ese periodo; por otra parte, y respondiendo al giro de la economía costarricense, los servicios en los últimos 5 años han generado un incremento porcentualmente mayor. El sector inmobiliario es el que ha mantenido un comportamiento más sostenido durante el periodo estudiado y el turismo ha presentado un menor aporte, particularmente en los últimos años. Pero dentro del esfuerzo del sector, lo relacionado con las declaratoria turística del ICT a inversiones relacionadas con marinas, hoteles, algunos restaurantes y otros desarrollos turísticos para que continúe aportando su valor agregado a la IED, el país debe de garantizar al ente inversionista estabilidad macroeconómica, baja inflación, acceso a tecnología en comunicación e información, adecuados y oportunos servicios públicos, infraestructura en aeropuertos, muelles y carreteras; así como personal capacitado y lo relacionado con la seguridad; aspectos que, en una mayoría, se encuentran en una crisis relativamente importante, particularmente por el problema de las finanzas públicas, el nivel educativo y la seguridad del país. 


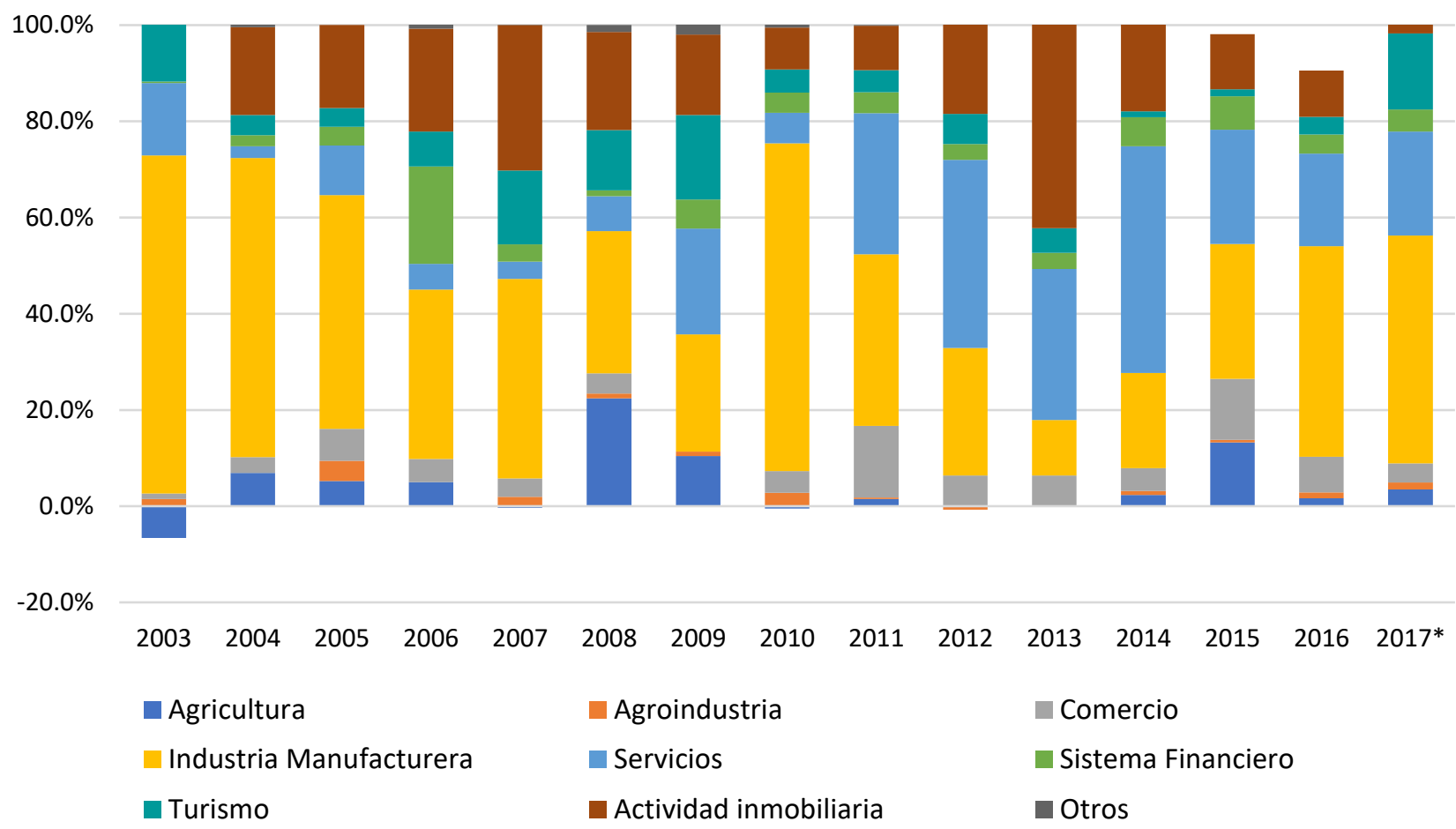

Figura 12. Costa Rica: IED por sectores de destino económico, 2003-2017 (valores porcentuales). Fuente: elaboración propia con datos de Banco Central de Costa Rica, Coalición Costarricense de Iniciativas de Desarrollo, Promotora de Comercio Exterior e Instituto Costarricense de Turismo (2019). Nota: *Datos preliminares acumulados al cuarto trimestre

Por otra parte, en la Tabla $\underline{3}$ y la Figura $\underline{13}$, se refleja el comportamiento del turismo receptor y el emisor, así como la actividad que se ha realizado dentro de la oferta turística, para el año 2016, último dato en que se encuentra esta información al momento de esta publicación.

Tabla 3

Costa Rica: Turismo receptor y emisor por tipo de viaje 2016

\begin{tabular}{lccccc}
\hline & $\begin{array}{c}\text { Placer, visita a } \\
\text { familiares }\end{array}$ & Salud & Negocios & Educación & Cruceros \\
\hline Turismo receptor & $66.0 \%$ & $13.4 \%$ & $12.7 \%$ & $7.7 \%$ & $2.2 \%$ \\
Turismo emisor & $60.2 \%$ & $0.9 \%$ & $35.0 \%$ & $3.9 \%$ & - \\
\hline
\end{tabular}

Fuente: elaboración propia con datos de Instituto Costarricense de Turismo \& Banco Central de Costa Rica (2018) 


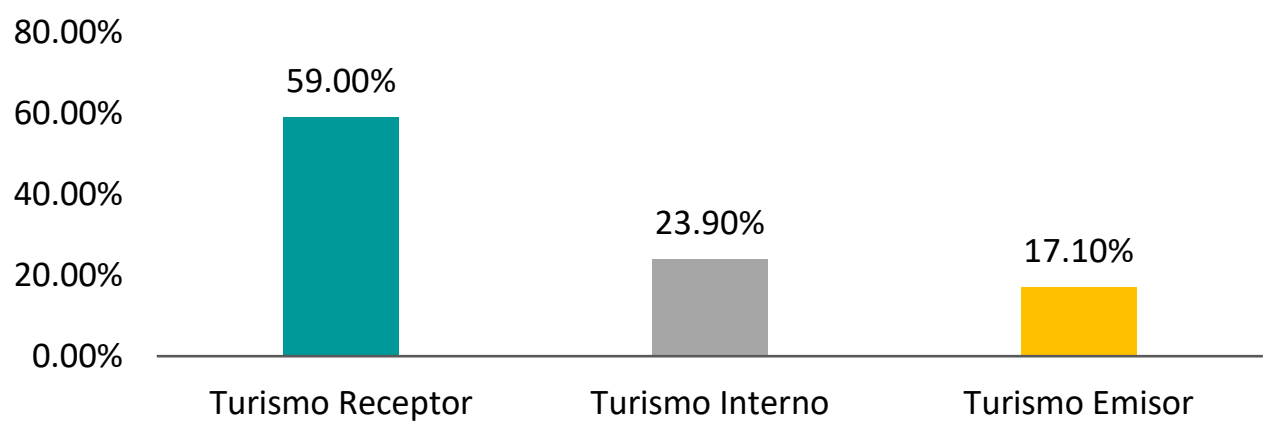

Figura 13. Costa Rica: Consumo turístico según tipo 2016 (valores porcentuales). Fuente: elaboración propia con datos de Instituto Costarricense de Turismo \& Banco Central de Costa Rica (2018).

El balance se inclina a favor del turismo receptor con un $59 \%$, de cual, la mayoría (el 66 \%), llega al país por placer o visita a familiares; las otras actividades de la oferta de país aún están muy alejados de este porcentaje, situación que puede reflejar que, si se cuenta con las condiciones necesarias, podrían potencializarse bastante, y fortalecer el valor agregado que este sector le dé al PIB en términos generales; desde un enfoque innovador e inclusivo como lo señala el Plan Nacional de Desarrollo Turístico de Costa Rica 2017- 2021, publicado en el 2017, donde se señalan algunos temas a impulsar para ampliar la oferta:

- La incorporación paulatina de nuevos modelos de negocio que incluyen tanto a empresas en el talento humano y generación de puestos de trabajo en el área de los servicios.

- La promoción y reconocimiento del capital social, el emprendedurismo y la asociatividad como formas de organización social necesarias para el turismo.

- Las oportunidades para el desarrollo y comercialización de nuevos productos turísticos.

- La participación informada de todos los agentes relevantes, así como un liderazgo político firme que facilite la participación. (Instituto Costarricense de Turismo, 2017a, p. 17)

Todo ello tomando en cuenta:

Su potencial de desarrollo le ha permitido al sector agregar nuevos productos y hacer mezclas para satisfacer nuevos intereses de la demanda, siempre en un marco natural y de sostenibilidad. Esta característica de flexibilidad le imprime dinamismo y permite a muchos actores locales incorporarse a la actividad turística con productos innovadores al generar con ellos dos características distintivas del modelo: la diversidad de actividades que se ofertan y su amplia dispersión en el territorio nacional. (Instituto Costarricense de Turismo, 2017a, p.19) 


\section{Cuenta Satélite de Turismo en Costa Rica:}

La siguiente información se obtuvo de la cuenta satélite de turismo (CST), elaborada por el Banco Central de Costa Rica. Contempla el período 2012-2016:

Constituye un esquema macroeconómico integrado, coherente y flexible, que se basa en definiciones, clasificaciones, reglas contables derivadas y armonizadas con el Sistema de Cuentas Nacionales, siendo una medida oficial, objetiva y fiable de la contribución económica del turismo.

La cuenta satélite es un estudio que se encuentra estrechamente vinculada con el marco central de la contabilidad nacional y de la balanza de pagos y, por tanto, constituye una extensión especializada del mismo, que permite dimensionar la contribución del turismo en la economía de una nación. Asimismo, posibilita la identificación de las actividades económicas que producen bienes y servicios que son destinados a los turistas.

Otro de los análisis del Banco Central fue la elaboración de la Matriz Insumo Producto, la cual permite medir efectos directos, indirectos e inducidos del turismo en la economía. (Banco Central de Costa Rica, 2018a, pp. 1-3)

\section{MIP, impacto económico del turismo}

De la información que se genera a partir de la cuenta satélite de turismo, relacionada con la composición del consumo, tanto del receptor como del turista nacional, se presenta la Figura 14.

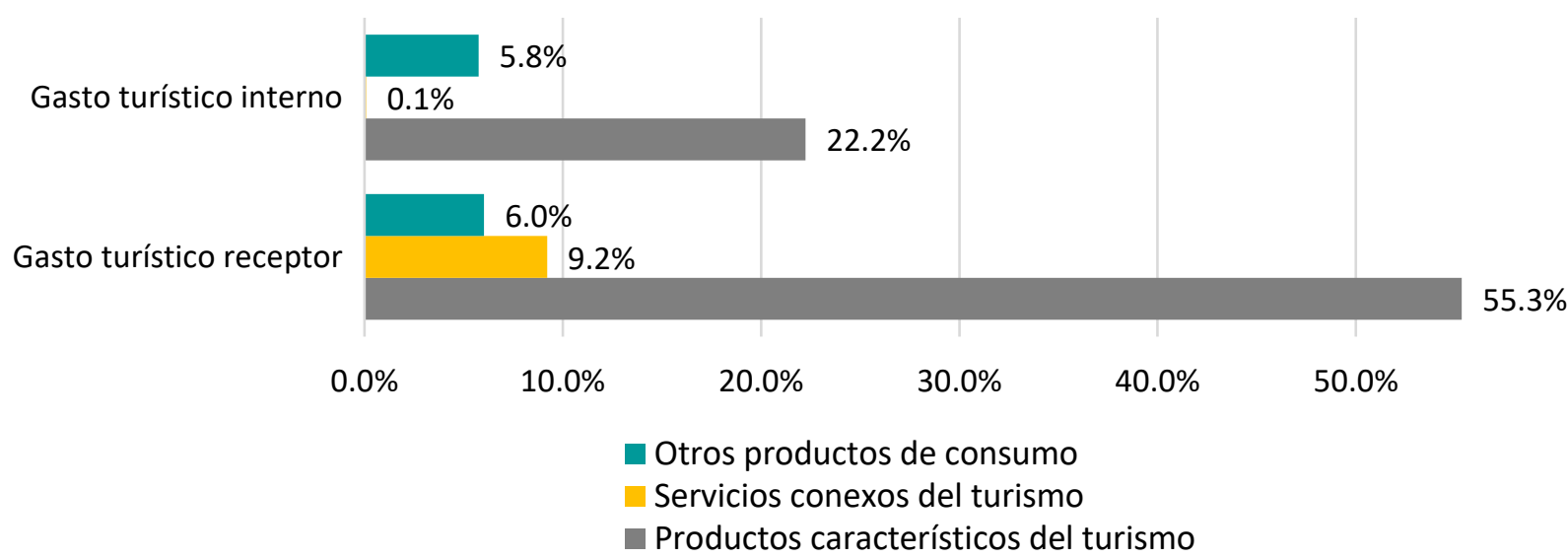

Figura 14. Costa Rica: Participación relativa de los productos de consumo en el consumo turístico interior, año 2016 (valores porcentuales). Fuente: elaboración propia con datos del Banco Central de Costa Rica (2018a). 
Como se puede observar, según los datos del Banco Central de Costa Rica, el gasto generado por las actividades turísticas (el cual se ha obtenido dividiendo el producto de consumo según tipo de gasto turístico entre el total del consumo turístico interno) proviene, en su mayoría, hasta en un $33 \%$ más por consumo receptor de productos propios del turismo, que lo aportado por el gasto interno; quienes nos visitan del extranjero tienen un aporte relativo mucho mayor que el consumo doméstico. Este aspecto debe de posibilitar la valoración de las políticas públicas que buscan potencializar la participación de residentes en las actividades turísticas nacionales, así como los precios a los que se ofrece la oferta interna.

En la dinámica del sector, se logró determinar mediante la cuenta satélite del turismo que elabora el Banco Central de Costa Rica, las cinco principales industrias que aportan más a la producción total, consumo intermedio y valor añadido bruto total, tal y como se aprecia en la Figura $\underline{15}$.

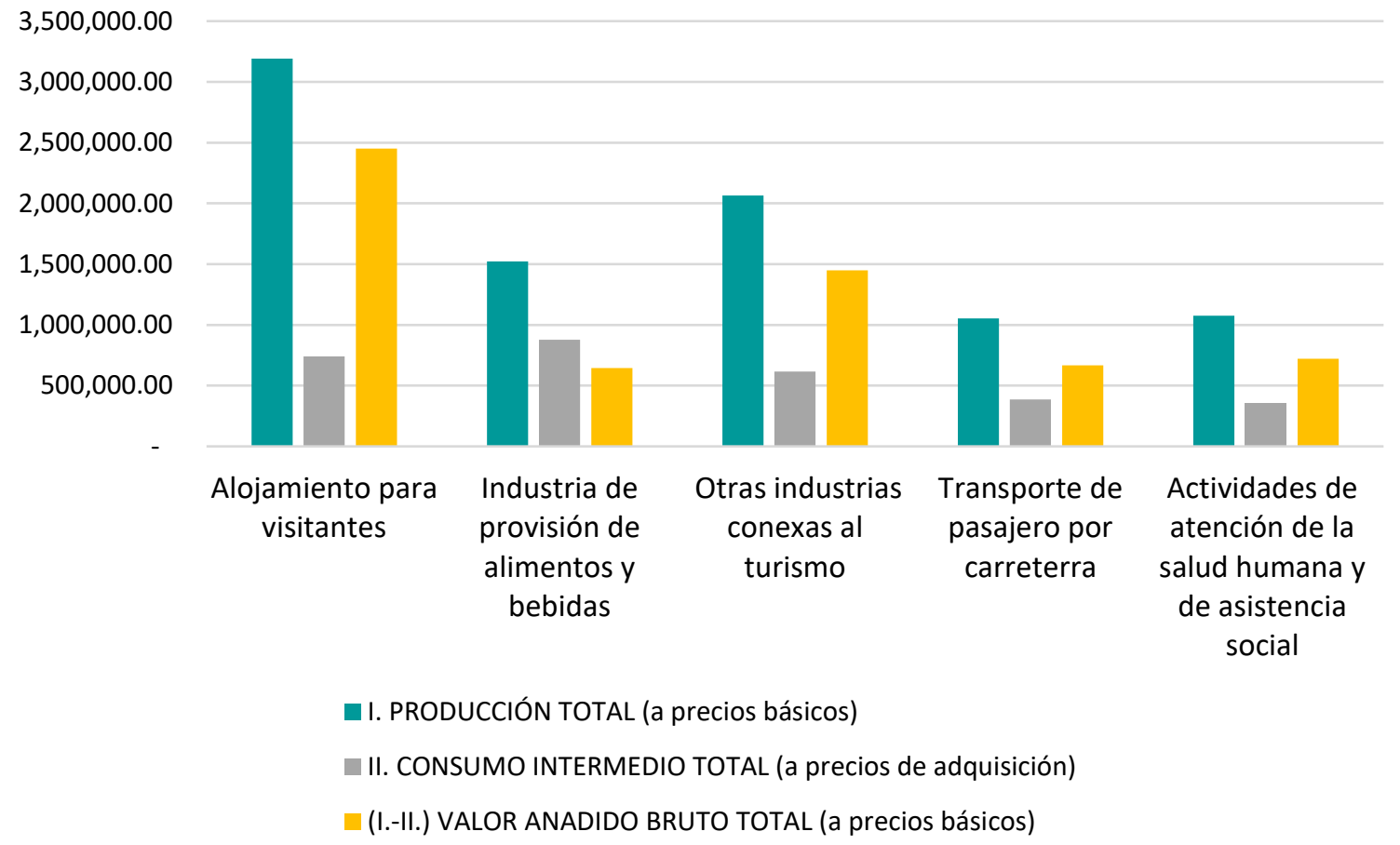

Figura 15. Costa Rica: Producción de las cinco principales industrias turísticas, año 2016 (millones de colones). Fuente: elaboración propia con datos del Banco Central de Costa Rica (2018a).

Como se puede observar en la Figura $\underline{15}$, de las cinco actividades productivas más dinámicas identificadas del sector turístico, el mayor productor y generador de valor es lo relacionado con el "alojamiento"; en segundo lugar, se encuentra "otras industrias conexas al turismo"; es relevante recordar la importancia del valor agregado, ya que en principio es la parte de los procesos que posibilitan más y mejores encadenamientos productivos y generación de valor para

Shirley Benavides Vindas 
la economía, de ahí su relevancia. El tercer lugar en los aspectos analizados lo ocupa la "industria de provisión de alimentos y bebidas", pero este factor es el que ocupa el primer lugar en el consumo intermedio total, situación que es comprensible por el tipo de actividad que llevan a cabo; ya que se convierten en los in puts del proceso productivo para la generación de bienes y servicios finales.

Otro aspecto relevante en este análisis es lo relacionado con la proporción turística vinculada a la oferta dirigida a sí misma y a otros sectores de la economía; esto, para las cinco principales actividades del turismo en el mercado interno, como se indica en la Figura $\underline{16}$ y refleja el siguiente comportamiento:

Agencias de viajes y otros servicios de reserva

Transporte aéreo de pasajeros

Servicios de alojamiento para visitantes

Alquiler de equipos de transporte

Actividades artísticas, de entretenimiento y recreativas

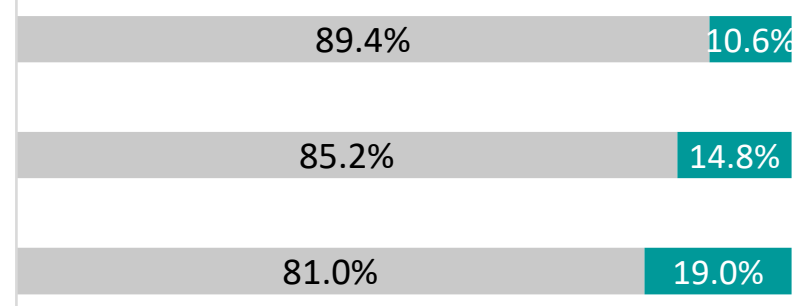

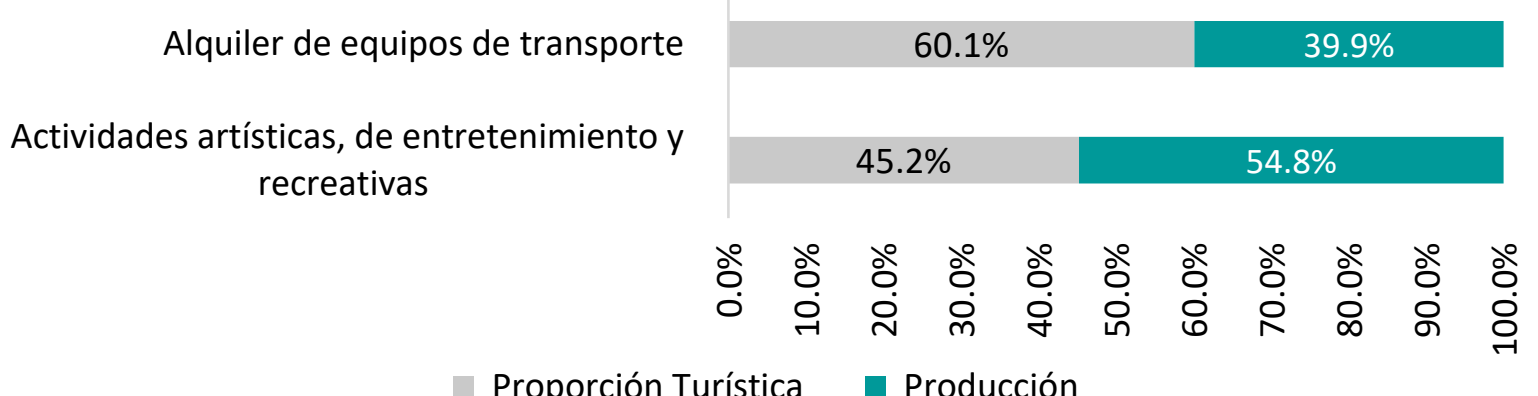

Figura 16. Costa Rica: Proporción turística y producción de las principales cinco industrias del turismo en la oferta interna, año 2016 (valores porcentuales). Fuente: elaboración propia con datos del Banco Central de Costa Rica (2018a).

Según la Figura $\underline{16}$, las "agencias de viajes y otros servicios de reservas", así como "transporte aéreo de pasajeros" son las actividades que proporcionalmente generan mayor valor dentro de toda la oferta turística a nivel nacional, con un $89,4 \%$ y un $85,2 \%$, respectivamente, aportando a otros segmentos diferentes al turismo el 10,6 \% y 14,8 \% restante. En contraposición, lo relacionado con "actividades artísticas, de entretenimiento y recreativas" se encadenan, en su mayoría, con otros sectores económicos, representando el $54,8 \%$ y solo un $45,2 \%$ dirigido al consumo turístico. En general se refleja un aporte por parte del sector que se estudia en este artículo, a otras actividades dentro de los esfuerzos de la producción nacional. 
En la Figura 17 se presenta el aporte al empleo tanto de las actividades turísticas como de las conexas.

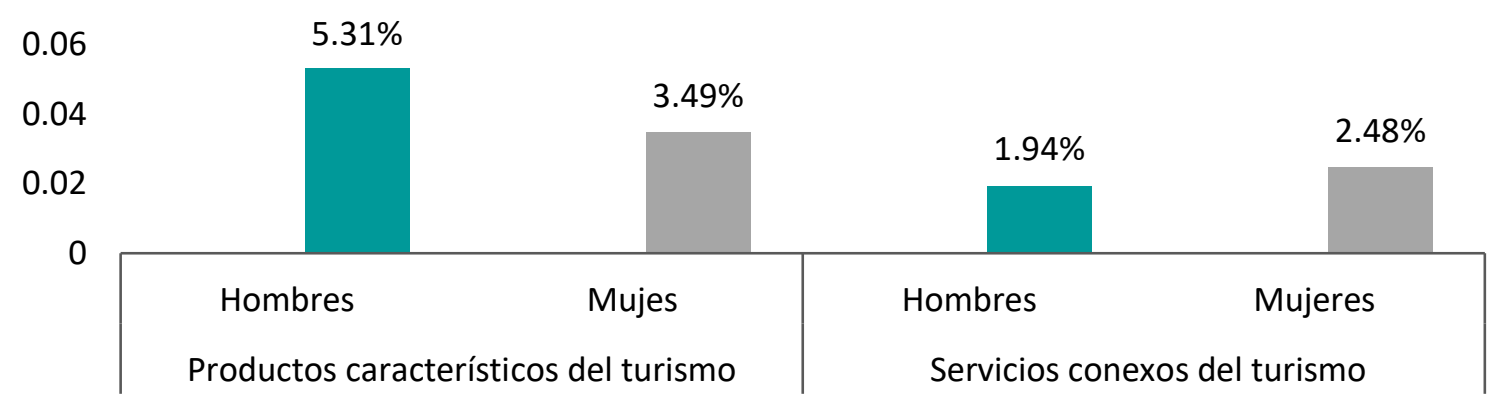

Figura 17. Costa Rica: Aporte al empleo de la industria turística según productos de consumo por sexo, 2016 (valores porcentuales). Fuente: elaboración propia con datos del Banco Central de Costa Rica (2018a).

El porcentaje de ocupados en industrias relacionadas con el turismo representa el 13,2\%, del total de empleo en Costa Rica -total de empleo Costa Rica es 2402 y las industrias turísticas contribuyen con 317 316-. Este se distribuye en productos característicos del turismo con un $8,8 \%$, o sea, $5,31 \%$ empleos ocupados por hombres y el 3,49 \% por mujeres; por su parte en los servicios conexos se invierte la participación por sexo, ellas ocupan un $2,48 \%$ y los varones un $1,94 \%$.

El porcentaje de los ocupados en las industrias relacionadas con el turismo representa el 13,2\% del 2019, dicha cifra está compuesta fundamentalmente por "productos característicos del turismo" y "servicios conexos del turismo"; en el primer caso, se presentan más puestos ocupados por hombres en contraposición del segundo, donde hay un mayor número de mujeres contratadas, pese a ello se presenta una menor proporción la diferencia por sexo, como se puede apreciar en la Figura $\underline{18}$. 


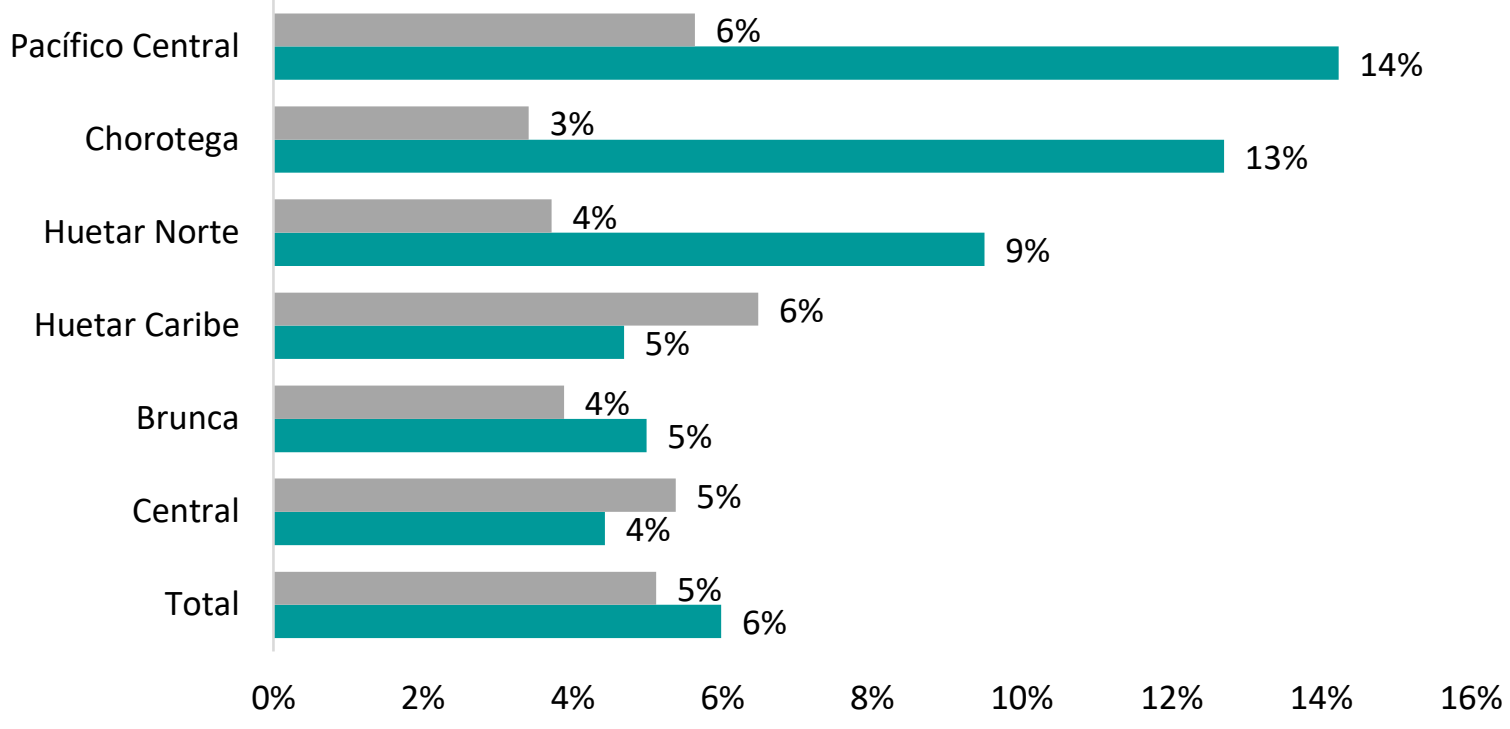

Transporte y almacenamiento $\quad$ Actividades de alojamiento y de servicio de comidas

Figura 18. Costa Rica: Número de personas ocupadas según actividades relacionadas con el turismo por región de planificación, año 2018 (valores porcentuales). Fuente: elaboración propia con datos de INEC- ENAHO (2018).

El total del aporte al empleo de las actividades turísticas registradas de manera directa por la Encuesta Nacional de Hogares del INEC, es de un 5\% para el transporte y almacenamiento y un $6 \%$ para alojamiento y servicios de comida, datos que con los recursos que Costa Rica tiene podrían potencializarse mucho más con una estrategia de desarrollo articulada al incremento de la demanda extranjera y la doméstica, de manera que generen mucho más impacto que la actual; pues, pese a todos los esfuerzos realizados, parece que no son suficientes como generadores de empleos.

Las composiciones de esos porcentajes se distribuyen entre las regiones de planificación del país; el de mayor incidencia es el Pacífico Central con un aporte del 20\%; seguido por la Chorotega con un $16 \%$ y el Huetar Norte con un 13\%; la Huetar Caribe, con todo el potencial cultural, geográfico, gastronómico y de playa que posee, aparece en el cuarto lugar con un $11 \%$.

La institucionalidad que atiende el turismo podría valorar el efecto que están teniendo, en las diversas regiones, las estrategias impulsadas en el sector y sus diversas actividades, pues su potencial, como se ha indicado supra, constituye un recurso para el desarrollo de los territorios. 
En Costa Rica, según los datos del BCCR de la Figura $\underline{19}$, el parque empresarial del sector turístico está compuesto de la siguiente manera:

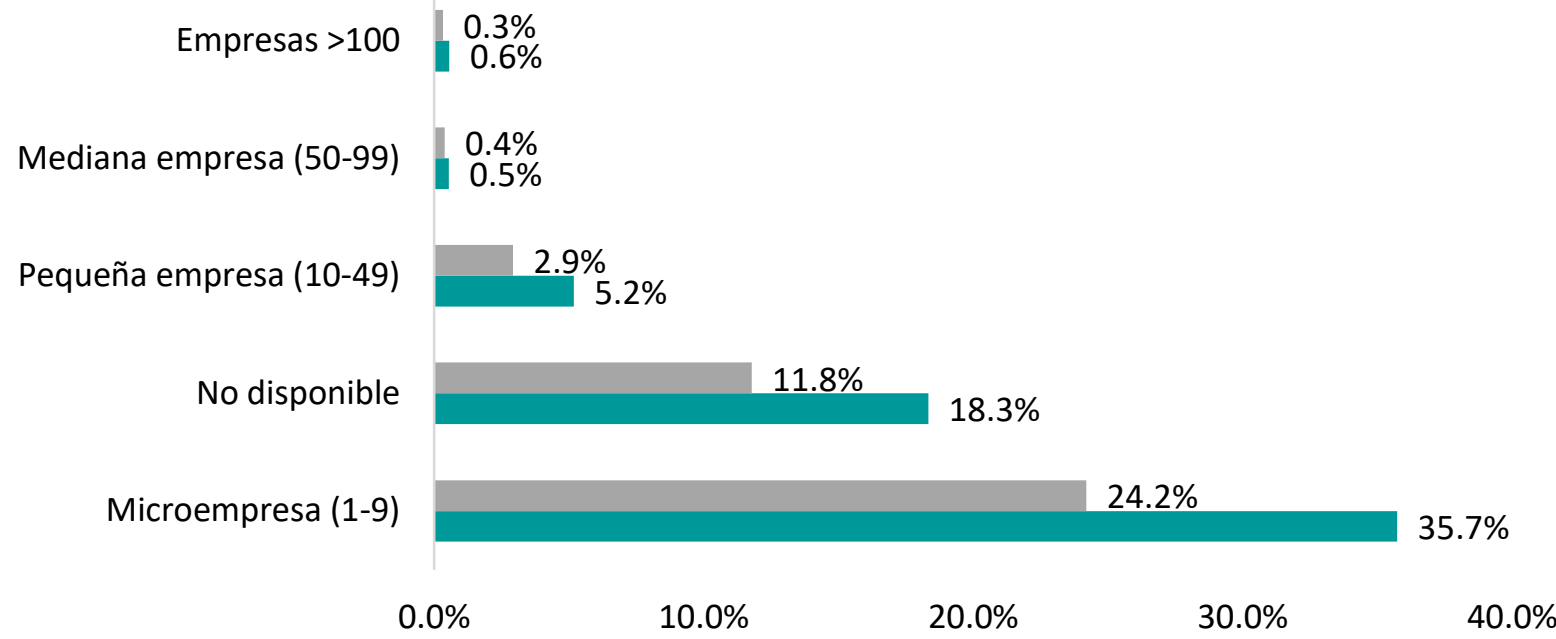

- Servicios conexos del turismo $\quad$ Productos carácterísticos del turismo

Figura 19. Costa Rica: Establecimientos de las industrias turísticas, clasificados según el número promedio de empleos (2016) (valores porcentuales). Fuente: elaboración propia con datos del Banco Central de Costa Rica (2018a).

Como se puede observar, las dos actividades que más aportan al turismo y a la economía en general son los "productos característicos del turismo" y "servicios conexos del turismo"; esta oferta la generan, en su mayoría, microempresas, como lo muestra la Figura 20. Esta situación debilita al sector, debido a las características de estas empresas, que por su tamaño y recursos no siempre cuentan con la capacitación y actualización que el mercado exige, lo que a su vez las lleva a tener deficiencias en el control de calidad -en servicios y productos-. Por otro lado, su capacidad de respuesta a la demanda y a proveedores es limitada; el acceso al financiamiento normalmente es complejo por la tramitología que se le solicita cumplir, lo que hace que las posibilidades de apalancamiento sean bajas; todas estas razones las ponen, en el mercado, en una situación de incertidumbre y con ciclos de vida limitados. Por lo anterior, las políticas públicas deben orientarse a fortalecerlas y a darles un tratamiento acorde con sus capacidades reales productivas, para que logren escalar en tamaño, calidad y sostenibilidad en el mercado, tanto nacional como internacional, ante un público consumidor cada vez más informado y exigente.

En la Figura 20, se presenta el aporte del turismo al PIB del país entre el 2012 y el 2016, según el Banco Central de Costa Rica. 


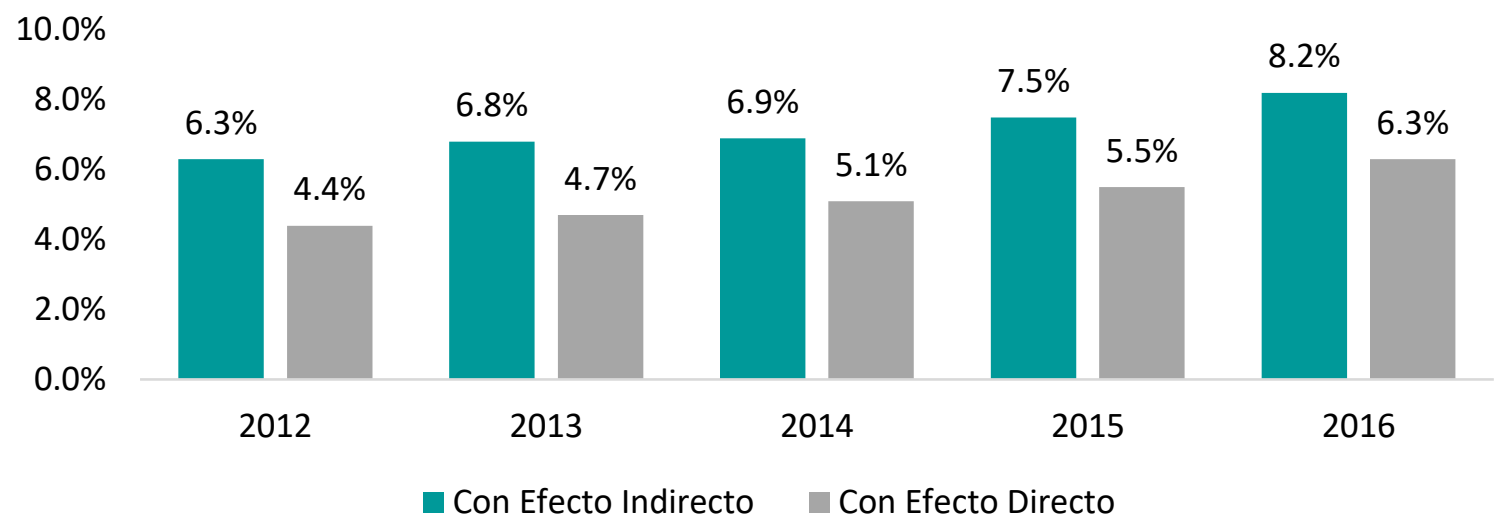

Figura 20. Costa Rica: Aporte del turismo al PIB 2012-2016 (valores porcentuales). Fuente: elaboración propia con datos de Instituto Costarricense de Turismo \& Banco Central de Costa Rica (2018).

El análisis de las repercusiones económicas que el turismo provoca sobre el PIB en los países es complejo, lo cual permite una discusión sobre las valoraciones de su impacto. La mejor manera de medir su importancia sobre el desempeño de la económica es la cuenta satélite de turismo, pese a ello, sus resultados apenas llegan a dar una visión de conjunto; por lo cual se ha determinado el efecto directo de este sector en la economía, el cual se asocia con la demanda que realizan turistas visitantes; por otra parte, se presenta el efecto indirecto, que se relaciona con los insumos que requieren los productores del resto de los sectores productivos. En ambos casos, Costa Rica ha venido presentando un incremento, durante los años con que se cuenta información, tanto a nivel directo como indirecto. Esto refleja, en alguna medida importante, el aporte del turismo al dinamismo económico, aspecto que da señales claras de la necesidad de contar con políticas públicas y estrategias que continúen potencializando los esfuerzos realizados en todas las actividades directas o encadenadas a la gran oferta del turismo en el país.

Por su parte, al comparar el aporte al PIB del sector turístico con el de otras actividades de la economía costarricense para el año 2016, se obtuvo lo expuesto en la Figura 21. El aporte del turismo al PIB es de un 6,3 \%, según los datos del BCCR, superando los servicios de informática, y el cultivo de banano. Este aporte es relevante, ya que el PIB es el principal indicador económico (debido a que mediante él es que se mide la cantidad de bienes y servicios se producen en un país durante un periodo que normalmente es anual). Para el caso en estudio, tiene que ver con las acciones relacionadas con la actividad turística de manera directa y, según las cuentas nacionales, estas son las de "alimentos, bebidas y hospedaje" y la de "transporte". 


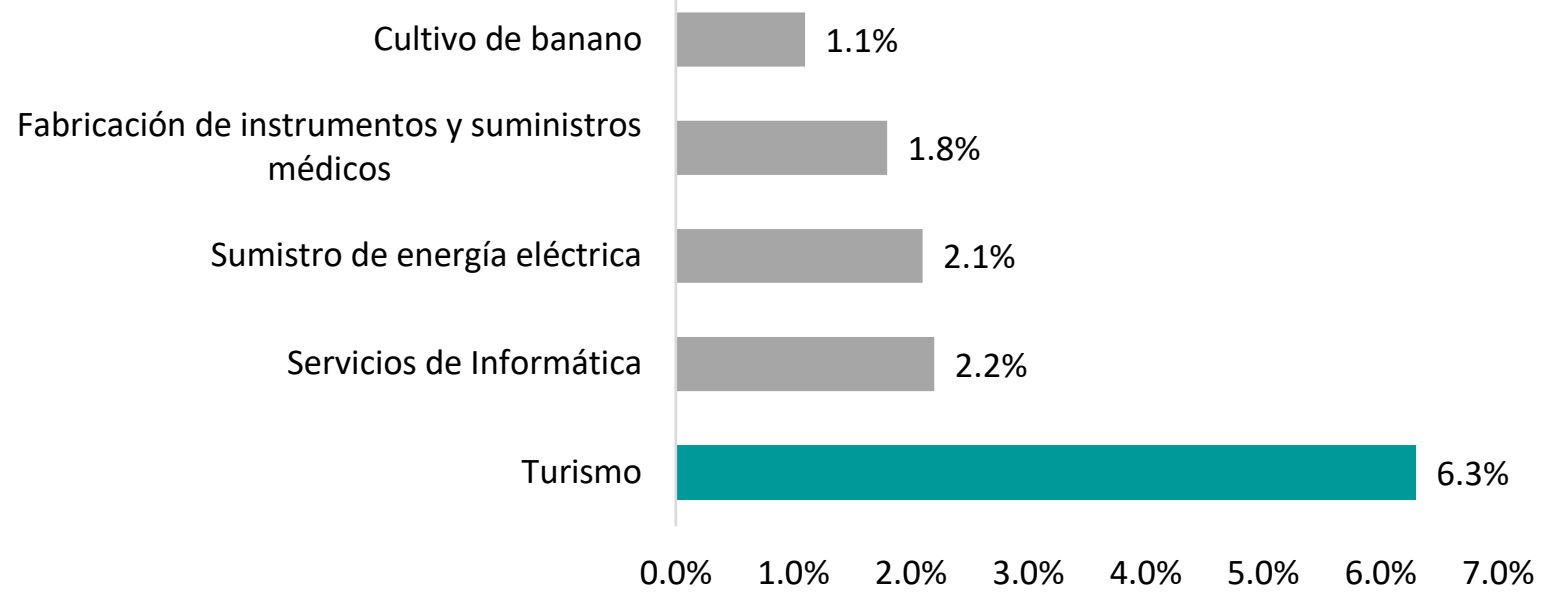

Figura 21. Costa Rica: Comparación del aporte del turismo al PIB con las principales actividades económicas, año 2016 (valores porcentuales). Fuente: elaboración propia con datos del Instituto Costarricense de Turismo \& Banco Central de Costa Rica (2018) y Banco Central de Costa Rica (2018b).

\section{Conclusiones}

La importancia del sector turístico a nivel mundial ha convergido de manera directa con el desarrollo de los territorios, situación que lo ha convertido en un motor clave del progreso socioeconómico; lo cual se ha reflejado en los planteamientos que la Asamblea General de las Naciones Unidas ha considerado al aprobar en la Agenda 2030 del Desarrollo Sostenible, y apoyar a alcanzar los objetivos relacionadas con los objetivos del milenio, particularmente el 8, 12 y 14 .

Por su parte, la mayoría del flujo de los turistas internacionales se dirige a los países de economías avanzadas ( $55 \%$ ) y el resto confluye en las economías emergentes.

El continente europeo sigue siendo el destino más gustado por el turismo internacional; seguido por Asia y el Pacífico, que se caracterizan por pertenecer a las economías emergentes e importantes del mundo. En la tercera posición se ubica el continente americano; dentro del cual, América Central ocupa el segundo lugar como destino turístico; este último aspecto debe considerarse en las estrategias de Costa Rica para impulsar el sector en estudio.

Es relevante indicar que Costa Rica posee una oferta de productos turísticos amplia y variada; dentro de la cual se cuenta con un sistema de parques nacionales y áreas protegidas, que cubren alrededor de un $25 \%$ del territorio nacional, con gran variedad de flora y fauna, que se estima contiene un $5 \%$ de la biodiversidad del mundo en menos del $0,1 \%$. 
El turismo genera más ingreso por divisas que las exportaciones de los cultivos tradicionales juntos, como: el banano, piña y café. Según el BCCR, el PIB Turístico: 1554 928,75 para el año 2016, representa un valor agregado a la producción interna de un 6,3 \%; último dato brindado por dicha institución.

De las cinco actividades productivas más dinámicas identificadas del sector turístico, el mayor productor y generador de valor es lo relacionado con el "alojamiento"; en segundo lugar, se encuentran "otras industrias conexas al turismo", lo que posibilita más y mejores encadenamientos productivos. En el tercer lugar se ubica la "industria de provisión de alimentos y bebidas", pero a su vez es la que ocupa el primer lugar en el consumo intermedio total.

El total del aporte al empleo de las actividades turísticas registradas de manera directa por la Encuesta Nacional de Hogares del INEC, es de un $5 \%$ para el transporte y almacenamiento y un $6 \%$ para alojamiento y servicios de comida. Al respecto, la institucionalidad que atiende las actividades debe revisar las articulaciones que llevan a cabo para impulsar el desarrollo de las regiones.

El porcentaje de personas ocupadas en industrias relacionadas con el turismo representa el 13,2\% del total de empleo en Costa Rica-total de empleo Costa Rica es 2402167 y de industrias turísticas contribuye con 317 316-, el cual se distribuye en productos característicos del turismo con un $8,8 \%$, o sea, 5,31\% empleos ocupados por hombres y el 3,49 \% por mujeres; por su parte, en los servicios conexos, se invierte la participación por sexo, ellas ocupan un $2,48 \%$ y ellos un $1,94 \%$.

Las dos actividades que más aportan al turismo y a la economía en general son: los "productos característicos del turismo" y "servicios conexos del turismo"; esta oferta la generan, en su mayoría, las microempresas del sector, con los riesgos que eso implica por ser las de mayor vulnerabilidad en el parque empresarial, junto con los emprendimientos.

Como lo señala el Plan Nacional de Desarrollo Turístico de Costa Rica 2017-2020; es relevante la consolidación del modelo de desarrollo turístico sostenible que conlleva a un enfoque de trabajo orientado a la dinamización y generación del desarrollo local desde el turismo, la competitividad de empresas, la sostenibilidad en el territorio y el desarrollo, y fortalecimiento de alianzas público-privadas a partir de mecanismos donde interactúan el sector público y la empresa privada.

Para lo anterior, es fundamental que la política de atracción de IED sea parte de una política industrial moderna que, además de procurar el cambio de la estructura productiva, facilite la innovación, inclusión y sostenibilidad, para mejorar el aporte al desarrollo nacional, mediante el fortalecimiento de encadenamientos productivos entre el sector y con aquellos que son conexos; 
todo ello apoyado por políticas públicas, para el fortalecimiento de dichos encadenamientos y de la IED.

Se debe ampliar la oferta turística con el propósito de aumentar el valor agregado de los diversos segmentos de consumidores, tanto del mercado local como del internacional; esto, apoyado del desarrollo de competencias para la creación de nuevos puestos de trabajo, que garanticen los derechos del personal trabajador; incluyendo las redes de cuido que posibiliten el ingreso de las mujeres al mercado laboral turístico.

\section{Referencias}

Banco Central de Costa Rica. (2018a). Cuenta Satélite de Turismo 2016. En Cuenta Satélite de Turismo. Recuperado de https://www.bccr.fi.cr/seccion-indicadores-economicos/cuentasat\%C3\%A9lite-de-turismo

Banco Central de Costa Rica. (2018b). Cuadro de oferta y utilización 2016. En Cuentas nacionales período de referencia 2012. Recuperado de https://www.bccr.fi.cr/seccion-cuentasnacionales-periodo-2012/cuentas-nacionales-periodo-de-referencia-2012

Banco Central de Costa Rica, Coalición Costarricense de Iniciativas de Desarrollo, \& Promotora de Comercio Exterior e Instituto Costarricense de Turismo. (2019). Inversión Extranjera Directa por sectores de destino. En Inversión en cifras. Recuperado de https://www.comex.go.cr/inversion-extranjera-directa

Instituto Costarricense de Turismo. (2017a). Plan Nacional de Desarrollo Turístico de Costa Rica 2017 - 2021. Recuperado de www.ict.go.cr/en/documents/plan-nacional-y-planesgenerales/plan-nacional-de-desarrollo/1071-plan-nacional-de-desarrollo-turistico-20172021/file.html

Instituto Costarricense de Turismo. (2017b). Anuario Estadístico de Turismo 2017. Recuperado de https://www.ict.go.cr/es/documentos-institucionales/estad\%C3\%ADsticas/informesestad\%C3\%ADsticos/anuarios/2005-2015/1103-2017-1/file.html

Instituto Costarricense de Turismo y Banco Central de Costa Rica (s. f). Divisas por concepto de turismo. Recuperado de https://www.bccr.fi.cr/seccion-indicadoreseconomicos/indicadores-econ\%C3\%B3micos 
Instituto Costarricense de Turismo y Banco Central de Costa Rica (2018). Presentación de la Cuenta Satélite de Turismo. En Cuenta Satélite de Turismo. Recuperado de https://activos.bccr.fi.cr/sitios/bccr/indicadoreseconomicos/CuentaSateliteTurismo/Pres entacion CST.pdf

Instituto Nacional de Estadísticas y Censos. (2018). Encuesta Nacional de Hogares 2018. Recuperado http://sistemas.inec.cr:8080/bincri/RpWebEngine.exe/Portal?BASE=ENAHO2018\&lang= esp

Organización Mundial del Turismo. (2011). Turismo internacional: Los primeros resultados de 2011 confirman la consolidación del crecimiento. Recuperado de http://media.unwto.org/es/press-release/2011-05-11/turismo-internacional-losprimeros-resultados-de-2011-confirman-la-consolid

Organización Mundial del Turismo. (2018a). ¿Por qué el turismo? Recuperado de http://www2.unwto.org/es/content/por-que-el-turismo

Organización Mundial del Turismo. (2018b). El turismo y los ODS. Recuperado de http://icr.unwto.org/es/content/el-turismo-y-los-ods

Organización Mundial del Turismo. (2018c). El turismo y la atenuación de la pobreza. Recuperado de http://step.unwto.org/es/content/el-turismo-y-la-atenuacion-de-la-pobreza

Organización Mundial del Turismo. (2018d). Panorama OMT del Turismo internacional. Edición 2018. Recuperado de: https://www.e-unwto.org/doi/pdf/10.18111/9789284419890

Organización Mundial del Turismo. (2017). Panorama OMT del Turismo internacional. Edición 2017. Recuperado de https://www.e-unwto.org/doi/pdf/10.18111/9789284419043 